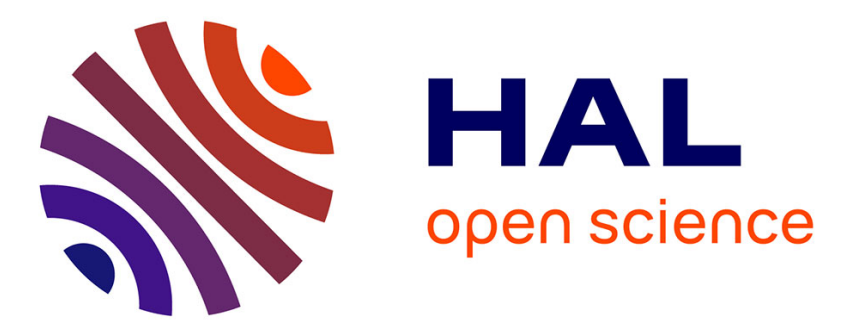

\title{
Results of UHF-radar observation of the nocturnal low-level jet for wind energy applications
}

Saïdou Madougou, Frédérique Saïd, Marie Lothon, Bernard Campistron, Cheikh F. Kebe

\section{- To cite this version:}

Saïdou Madougou, Frédérique Saïd, Marie Lothon, Bernard Campistron, Cheikh F. Kebe. Results of UHF-radar observation of the nocturnal low-level jet for wind energy applications. Acta Geophysica, 2012, 60 (5), pp.1454-1473. 10.2478/s11600-012-0062-4 . hal-00766788

\section{HAL Id: hal-00766788 \\ https://hal.science/hal-00766788}

Submitted on 11 Nov 2021

HAL is a multi-disciplinary open access archive for the deposit and dissemination of scientific research documents, whether they are published or not. The documents may come from teaching and research institutions in France or abroad, or from public or private research centers.
L'archive ouverte pluridisciplinaire HAL, est destinée au dépôt et à la diffusion de documents scientifiques de niveau recherche, publiés ou non, émanant des établissements d'enseignement et de recherche français ou étrangers, des laboratoires publics ou privés. 


\title{
Results of UHF Radar Observation of the Nocturnal Low-Level Jet for Wind Energy Applications
}

\author{
Saïdou MADOUGOU ${ }^{1}$, Frederique SAÏD ${ }^{2}$, Bernard CAMPISTRON ${ }^{2}$, \\ Marie LOTHON ${ }^{2}$, and Cheikh F. KEBE ${ }^{3}$ \\ ${ }^{1}$ Ecole Nationale Supérieure, Université Abdou Moumouni, Niamey, Niger \\ e-mail: nassara01@yahoo.fr (corresponding author) \\ ${ }^{2}$ Université de Toulouse, Laboratoire d'Aérologie, CNRS UMR, France \\ e-mails: frederique.said@aero.obs-mip.fr, bernard.campistron@aero.obs-mip.fr, \\ marie.lothon@aero.obs-mip.fr \\ ${ }^{3}$ Ecole Supérieure Polytechnique, Dakar (Fann), Sénégal \\ e-mail: cmkebe@gmail.com
}

\begin{abstract}
We use two series of eight-month UHF radar observations collected during the dry and wet seasons of AMMA field campaign. The ultimate goal is to do preliminary work to know whether the lowest layers are suitable for wind energy applications. Surface wind is usually weak in West Africa, but the regular occurrence of a nocturnal low level jet (NLLJ) could provide interesting conditions for wind energy. This work is two-fold: it first aims at improving our knowledge about the NLLJ in West Africa regarding its structure and its variability during the year. Then, special attention is paid to the first $200 \mathrm{~m}$ agl, to study the possibility to use the sub-jet wind as a source of energy. A set of enhanced radiosoundings is taken to help to understand the dynamics and thermodynamics and to find a way to extrapolate the wind at low level, where the UHF radars do not provide data.
\end{abstract}

Key-words: UHF radar, wind potential in Sahel, nocturnal low level jet, Sahel meteorology, wind profiles. 


\section{INTRODUCTION}

The use of wind energy in Africa is less developed than in other continents. In spite of the huge potential over Africa with the world's best sites in the north and the south of the continent, statistics show that only $906 \mathrm{MW}$ $(0.5 \%$ of the worldwide capacity) of wind power plant have been installed (World Wind Energy Association 2010). Among these wind power plants installed, 155 MW were added in 2010 (169 MW in 2009) in three countries, Egypt, Morocco, and South Africa.

Except for some specific areas such as coastal or mountainous sites (Kébé et al. 2008, Ajayi 2009), surface winds are usually rather weak in West Africa (Adekoya and Adewale 1992, Janicot and Sultan 2007, Janicot et al. 2008). As an example, we present in Fig. 1a, $10 \mathrm{~m}$ surface winds measured at Niamey airport (Niger, $13^{\circ} 29^{\prime} \mathrm{N}, 2^{\circ} 10^{\prime} \mathrm{E}$ ). They are shown for 4 different months. Most of the time, winds are weaker than $3 \mathrm{~m} / \mathrm{s}$, which is characteristic of a class 1 station, according to the Power Classes proposed by Archer and Jacobson (2003). According to these authors, who made an extensive study of the wind potential in the United States, class $1(10 \mathrm{~m}$ winds lower than $4.4 \mathrm{~m} / \mathrm{s})$ and class $2(10 \mathrm{~m}$ winds between 4.4 and $5.1 \mathrm{~m} / \mathrm{s})$ are not suitable for extended wind farms. Note that this does not prevent wind energy being used for local needs.

In West Africa, Ngala et al. (2007) used $10 \mathrm{~m}$ wind observations during ten years in Nigeria $\left(11^{\circ} 50^{\prime} \mathrm{N}, 13^{\circ} 09^{\prime} \mathrm{E}\right)$ and found class 1 winds. Lothon et al. (2008) reported mean surface winds weaker than $2.5 \mathrm{~m} / \mathrm{s}$ in Central Benin; $\left(9^{\circ} 40^{\prime} \mathrm{N}, 1^{\circ} 40^{\prime} \mathrm{E}\right)$. Adekoya and Adewale (1992) who analyzed the wind potential in Nigeria, reported surface winds varying between 1.5 and $4.1 \mathrm{~m} / \mathrm{s}$. That is why, up to now, the main use of wind energy in West African countries has been electricity generation and water pumping in rural areas, sometimes not supplied by baseload fossil energy systems. Nevertheless, West African countries are making substantial efforts to develop renewable energy on a larger scale and a Wind Energy Atlas is being built up and constantly improved (Youm et al. 2005, Kasbadji-Merzouk and Merzouk 2006, Ajayi 2009).

In this context, there is a potential that, to the best of our knowledge, has not been investigated in West Africa. Several studies of upper winds showed that semi-arid areas experience frequent low level jets (LLJ) in the low troposphere (Parker et al. 2005, Washington et al. 2006, Lothon et al. 2008, and Abdou et al. 2010). Among the various kinds of LLJs that have been described in the literature (Stensrud 1996), we focus here on the LLJ that occurs nightly (NLLJ) and that is linked to an inertial oscillation around the ageostrophic wind vector with a period of $2 \pi / f$ (where $f$ is the Coriolis parameter) in the framework of Blackadar's (1957) model. 
(a)
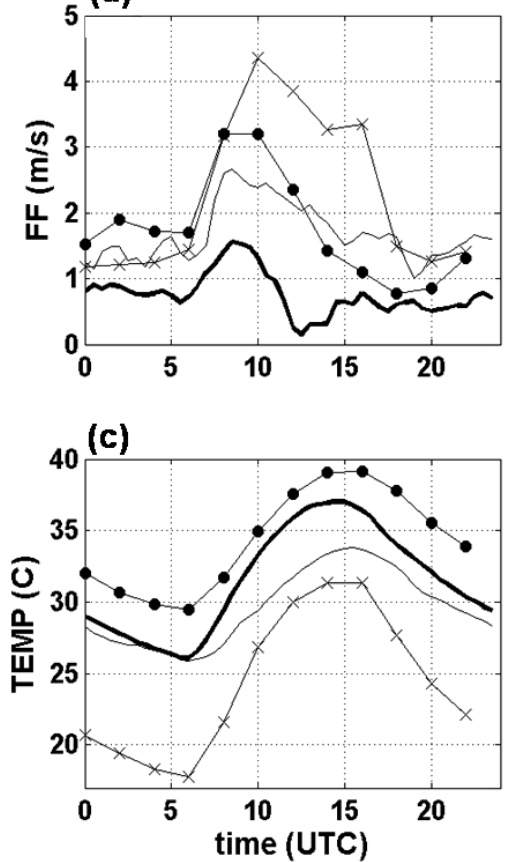

(b)
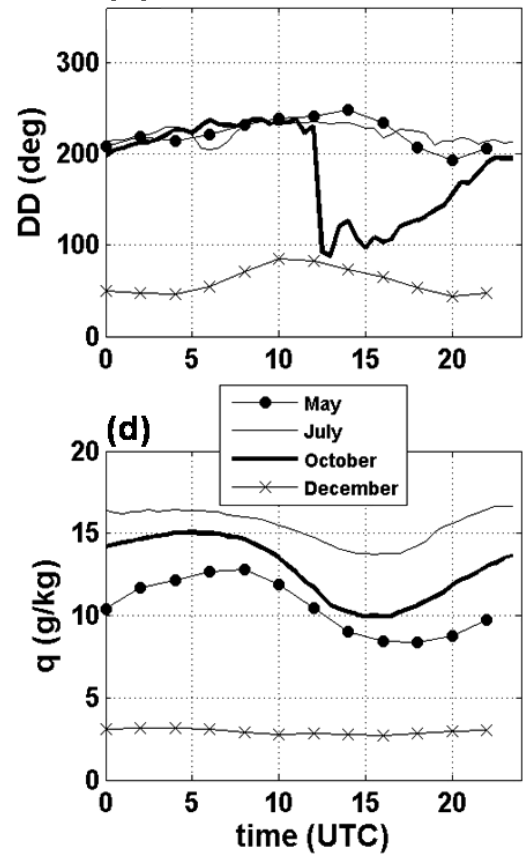

Fig. 1. Composite days for four characteristic periods of 2006, observed at Niamey airport ground station: (a) wind speed, (b) wind direction, (c) temperature, and (d) water vapor mixing ratio.

During the daytime, the atmospheric boundary layer wind is usually weak, due to strong turbulence mixing in the convective boundary layer. The wind results from the balance between Coriolis force, shear stress and forces due to the pressure gradient. As turbulence decays rapidly in the afternoon, the only forces remaining (Coriolis and pressure gradient force) are no longer balanced, generating an inertial acceleration as the air flows down the large pressure gradient (Blackadar 1957). This effect is amplified during summer, in the Sahel area, by the fact that a zone of low pressure, located over the Sahara, is deepest in late afternoon (Racz and Smith 1999, Parker et al. 2005, Lavaysse et al. 2009). The strength of the wind depends on the degree of departure from ageostrophic balance at sunset (Parker et al. 2005, Shapiro and Federovich 2010), which is why the peak of the accelerated wind occurs in the lower layers, where the turbulent stress divergence is the largest (Blackadar 1957, Lundquist 2003). Due to increased stress divergence at the surface (Mahrt 1981) and strong stratification, the jet is decoupled from the surface, in agreement with the surface observations described above. 
As night proceeds, the stable nocturnal layer deepens, mostly on account of radiative cooling, and the jet intensifies while veering and being shifted towards higher levels. So this evolution proceeds until sunrise, when convection appears again and gradually mixes the air. However just before sunrise, the vertical profile of temperature is very often nearly adiabatic within the first $100-200 \mathrm{~m}$. This has already been highlighted by Bonner (1968) and is linked to the strong vertical wind-shear generated beneath the jet (Gifford 1952). As soon as convection arises after sunrise, there is a rapid mixing between the surface momentum and the LLJ shear momentum which explains the morning peak of the surface wind, as seen in Fig. 1a around 09:00 UTC.

Several works have previously been published to describe the nocturnal LLJ in semi-arid areas of West Africa. Parker et al. (2005) studied the diurnal cycle of the West African monsoon winds in the Niamey area, using experimental data from the HAPEX-Sahel 1992 and JET 2000 experiments, two years of pilot balloon wind data and European Centre for Medium-range Weather Forecast (ECMWF) ERA40 reanalysis at 1.125-degree resolution for the period 1979-2001. They highlighted the intensification of winds overnight, especially during the transition period before the full monsoon season, and showed wind values peaking at 8 or $14 \mathrm{~m} / \mathrm{s}$ according to the period, at about $600 \mathrm{~m}$. Washington and Todd (2005) used reanalyses (National Center for Environmental Prediction (NCEP) and ERA40 dataset) over northern Chad $\left(17^{\circ} \mathrm{N}, 18^{\circ} \mathrm{E}\right)$ and found a low-level jet persisting at night throughout the year except in August, and peaking near $925 \mathrm{hPa}$, with strongest values in January. In January, typical zonal monthly means were around $8 \mathrm{~m} / \mathrm{s}$ whereas they were only around $4 \mathrm{~m} / \mathrm{s}$ during the summer months. Washington et al. (2006) analysed the data from the 2005 BODEX experiment, over the Bodélé depression in Chad $\left(16^{\circ} 53^{\prime} \mathrm{N}, 18^{\circ} 33^{\prime} \mathrm{E}\right)$ in relationship with dust emission and transport. They noticed that the LLJ was present every day during the February-March experiment. Abdou et al. (2010), using a network of 4 SODARS in the environs of Niamey, measured the wind diurnal cycle between 30 and $600 \mathrm{~m}$ with a high vertical resolution, during the 2006 rainy season. In accordance with surface studies, they measured winds peaking at $5 \mathrm{~m} / \mathrm{s}$ at around 10:00 UTC at $30 \mathrm{~m}$ and lower than $3 \mathrm{~m} / \mathrm{s}$ at night. At $100 \mathrm{~m}$, the diurnal cycle was not particularly marked. In contrast, above $100 \mathrm{~m}$, the wind increased at night and went on rising, up to $12 \mathrm{~m} / \mathrm{s}$ at $600 \mathrm{~m}$ at 06:00 UTC, to drop to $7 \mathrm{~m} / \mathrm{s}$ in the afternoon. Finally, Lothon et al. (2008), using rawisondes and wind profiler radar observations in Niamey, made a statistical study of the nocturnal jet maximum during 2006. They showed that the jet blew throughout the year.

The present work aims at extending the study of the characteristics and the variability of the low level wind in the Sahel area while contributing new statistics of the LLJ obtained with a UHF profiler. The focus is especially on 
the dynamic and thermodynamic properties of the very low layers to determine whether wind blowing there is suitable for wind energy applications. The objective is clearly not to provide new explanations of the low level nocturnal jet mechanism since the latter has been abundantly studied all over the world (reviews from Stensrud (1996), including profiler observations; climatology from Bonner (1968), Whiteman et al. (1997), and Song et al. (2005) for the US Great Plains; climatology from May 1995 over Australia, describing the seasonal effect of the Australian monsoon. The last three authors also used profiler observations). In spite of the interest in wind energy applications manifested by these various authors, we did not find any wind energy study especially dedicated to the LLJ potential. However, numerous studies, such as the one performed by Archer and Jacobson (2003) to quantify US wind power at $80 \mathrm{~m}$, include LLJ events, without actually saying so. In addition, Storm and Basu (2010) highlighted the critical need to document the effect of wind shear and directional shear on wind turbines, in case of LLJs.

In this region of very weak surface winds, as in the whole Sahel area, the idea is to try to know whether there would be an opportunity for wind measurements using the LLJ around $100-150 \mathrm{~m}$. The present paper is organized as follows. In Section 2, we present the set of experimental means, in Bamako (Mali) and in Niamey, including the percentage of data availability and a comparison between the radar and radiosounding data in Niamey. In Section 3, we describe the large scale forcing in West Africa and its seasonal variability. Section 4 focuses on the diurnal cycle of the low level wind, including a statistics of the nocturnal LLJ. We try here to explain the seasonal variability in the level and intensity of the peak maximum. Section 5 studies the shape of the wind profiles in the lower layers in relationship with thermodynamics, using a rawisonde enhanced dataset, with the aim of extrapolating the UHF wind measurements to other levels. The lowest data provided by the radars is for $150 \mathrm{~m}$, which corresponds to the lowest level where a marked LLJ peak appears according to Abdou et al. (2010). A $150 \mathrm{~m}$ hub height is not relevant for the present time turbine technology, which is why we explore a lower level. An upper level is also investigated, to give an idea of the wind shear between the extremities of the turbine blades. Turbulence, as defined in the Wind Resource Assessment Handbook (AWS Scientific Inc. 1997), can produce damaging effects on wind turbines. It is discussed along with other detrimental effects on rotors.

\section{UHF RADAR DATA SET, PROCESSING, AND VALIDATION}

In this section, we first describe the data sources used in the study before explaining the UHF radar data processing and its validation. 


\subsection{Data description}

The data used covered two series of eight-month observations made during the dry and wet seasons of the African Monsoon Multidisciplinary Analysis (AMMA) field campaign in West Africa. AMMA was an international project aimed at improving knowledge and understanding of the West African monsoon and its variability, with emphasis on daily-to-inter-annual timescales (Redelsperger et al. 2006, Lebel et al. 2010). The region covered by AMMA field observations extends from the edge of the Atlantic Ocean in West Africa to the coast of Central Africa and includes Lake Chad and the Gulf of Guinea. During the Enhanced Observing Period (EOP) which lasted from 2005 to 2007, the rawinsonde network was improved and other instrumentation, such as wind profilers and meteorological or hydrological ground stations was implemented in order to document the annual cycle of the surface conditions and atmosphere and to study the surface memory effects on the seasonal scale.

Here, we use measurements from two wind profiler radars installed at Bamako $\left(12^{\circ} 32^{\prime} \mathrm{N}, 7^{\circ} 57^{\prime} \mathrm{W}\right.$ and at $380 \mathrm{~m}$ asl, south west Mali) and at Niamey $\left(13^{\circ} 29^{\prime} \mathrm{N}, 2^{\circ} 10^{\prime} \mathrm{E}\right.$ and $227 \mathrm{~m}$ asl, south west Niger). Both Bamako and Niamey are situated in the Sahel band $\left(13^{\circ}\right.$ to $\left.17^{\circ} \mathrm{N}\right)$ in West Africa and they are roughly $100 \mathrm{~km}$ apart in latitude.

In Bamako, the UHF PCL $1300(1290 \mathrm{MHz})$ radar, installed at the airport by ASECNA (Agency for Aerial Navigation Safety in Africa and Madagascar) to monitor the nocturnal strong low-level wind shears that regularly compromise the safety of aircraft on landing and take-off, was operated without interruption from 4 March until 29 December 2005 except for an inactive period from May to June due to technical problems. After December 2005, it suffered from technical problems and, even after repair, its data were no longer recorded. This radar was the first wind profiler radar ever installed in West Africa. It has three antennas: one used for the vertical measurements and the other two for oblique measurements.

The second radar (915 MHz) was installed in March 2006 at Niamey airport during the AMMA EOP in the framework of the US ARM program (Atmospheric Radiation Measurements; Miller and Slingo 2007) and provided data from 4 April 2006 to 6 January 2007, except for an inactive period from 17 June to 2 July. This radar has 5 antennas (one vertical and four oblique).

A third radar, the MIT C-band Doppler radar (5.37 cm wavelength) was also installed at Niamey airport by Massachusetts University for the AMMA experiment, from July to September 2006 (Lothon et al. 2011). Derivation of the 3D wind field from the MIT single-Doppler radar data was based on the version of the multiple-Doppler synthesis and continuity adjustment 
technique (Bousquet and Chong 1998) adapted to ground-based radars (Chong and Bousquet 2001). The July horizontal wind measurements obtained with this method were compared, in the present work, to the Niamey UHF measurements.

Some radiosounding data were also used to check the radars' performance and to study the fine structure of dynamics and thermodynamics in the lower layers. Those data were collected by ARM at Niamey. From 25 January to 31 December 2006, 4 rawisondes were launched per day at Niamey at 06:00, 12:00, 18:00, and 24:00 UTC. The rate was further improved during some intensive observation periods with 8 rawisondes per day (Parker et al. 2008). The vertical resolution was $11 \mathrm{~m}$ on average in Niamey and could vary between 6 and $22 \mathrm{~m}$ according to the stability conditions. At Bamako, 2 radiosoundings were made per day, at 00:00 and 12:00 UTC in 2005 (Parker et al. 2008) but their vertical resolution was too poor for us to use them as a comparison with the UHF.

In the present paper, we will also use the surface data from the ARM ground station at Niamey airport to characterize the different seasons of the year (Miller and Slingo 2007).

\subsection{UHF data processing}

UHF radar measures wind vertical profiles and back-scattered signal strength between about 0.1 and $3-5 \mathrm{~km}$, depending on the conditions of the atmosphere (Jacoby-Koaly et al. 2002, Heo et al. 2003). It operates by transmitting electromagnetic energy into the atmosphere and measuring the strength and frequency of the backscattered energy. It can work both in clear air and during precipitation events. In clear air, the atmospheric signal is due to the backscattering by spatial irregularities of the air refractivity index at the scale of half the radar wavelength when the source of the fluctuations comes from turbulent mixing which follows the behaviour of the Kolmogorov inertial subrange. Air refractivity depends on temperature and humidity, the latter dominating in the lower atmosphere (Heo et al. 2003).

The measurements made by the two Doppler profilers were based on a repetitive sequence cycling over the five/three beams, of 5.23/2.5 min duration, respectively, in Niamey and Bamako, with the possibility of a high and low collection mode. The vertical resolution was $60 / 150 \mathrm{~m}$ for the low mode in the range of $150 \mathrm{~m}$ to $2 \mathrm{~km}$ and $420 / 375 \mathrm{~m}$ for the high mode in the range of $300 \mathrm{~m}$ to $6 \mathrm{~km}$ for Niamey/Bamako, respectively. The low mode will be mostly used in this work. The same data processing was applied for both profilers. The three wind components were deduced, for each cycle of measurements, from the mean Doppler radial velocity measured on the vertical and tilted planes with the assumption of local horizontal field homoge- 
neity. Three radial velocities were required to retrieve the three wind components. In the case of the Niamey radar, information was redundant, as there were 5 beams, which allowed erroneous spectra to be discarded. Power spectra of the wind energy were averaged hourly to create wind averages that were considered to be reliable to within $1 \mathrm{~m} / \mathrm{s}$ (Coulter et al. 1999). The difficulty of operating with profiler radars used in clear air is that the meteorological echoes (produced by the wind) are very faint relative to the noise. So the data processing is rather complex (see Jacoby-Koaly et al. 2002 who explain the method used for ground clutter echo decontamination).

Values of the data recovery rate are shown for each radar in Fig. 2, at $150 \mathrm{~m}, 1$ and $2 \mathrm{~km}$ agl, for the rainy (July) and dry (December) seasons. The data recovery rate is defined as the number of valid data records collected versus the number possible over the selected period (month). It does not include the periods when the radars were not working. The best periods for data retrieval were during the rainy season, i.e., between June and October at both locations. During these periods, the availability was close to $100 \%$ up to $1000 \mathrm{~m}$ in Niamey (and even $1500 \mathrm{~m}$, not shown) and close to $80-90 \%$ in Bamako (Fig. $2 \mathrm{a}$ and $\mathrm{b}$ for July). The data recovery decreases when the water vapour mixing ratio $q$ decreases, i.e., at altitude or during the dry season, as the radar reflectivity is linked to water vapour fluctuations and turbulence. The lower the $q$ the lower the fluctuations. During the dry months, $q$ is very low (around $3 \mathrm{~g} / \mathrm{kg}$ below $2000 \mathrm{~m}$ according to Lothon et al. 2008). A diurnal cycle appears in the data recovery rate at $1000 \mathrm{~m}$, with some minima at dawn and dusk. At dawn, this minimum is at the time of the LLJ peak occurrence. In fact, the minimum appears at all levels situated over $600 \mathrm{~m}$ agl in Niamey and $430 \mathrm{~m}$ in Bamako, i.e., around $100 \mathrm{~m}$ above the LLJ peak level in Niamey and around $100 \mathrm{~m}$ below it in Bamako (not shown). It is probably the turbulence linked to the LLJ that favors echoes below the LLJ peak. If the LLJ was not there, the echoes would probably be too faint to be detected. During the daytime, echoes can be detected again due to turbulent mixing. The decrease in data recovery range that is encountered near dusk is far less understandable.

Particular attention should be paid to the data recovery rate at lower levels since these are the levels that are the most affected by ground clutter echoes and they are also the levels that are going to be used in what follows. The Niamey lowest level $(150 \mathrm{~m} \mathrm{agl})$ provides good data availability of $90-100 \%$ most of the time (Fig. 2b and d) and $60-80 \%$ in April and May. The Bamako low level data coverage is a little worse since it can decrease to $60 \%$ during some periods of the day, even during summer (Fig. 2a). In December, the radar started showing the first signs of malfunction (Fig. 2c) and the recovery rate remained between $60-70 \%$ at $150 \mathrm{~m}$. Note, however, 

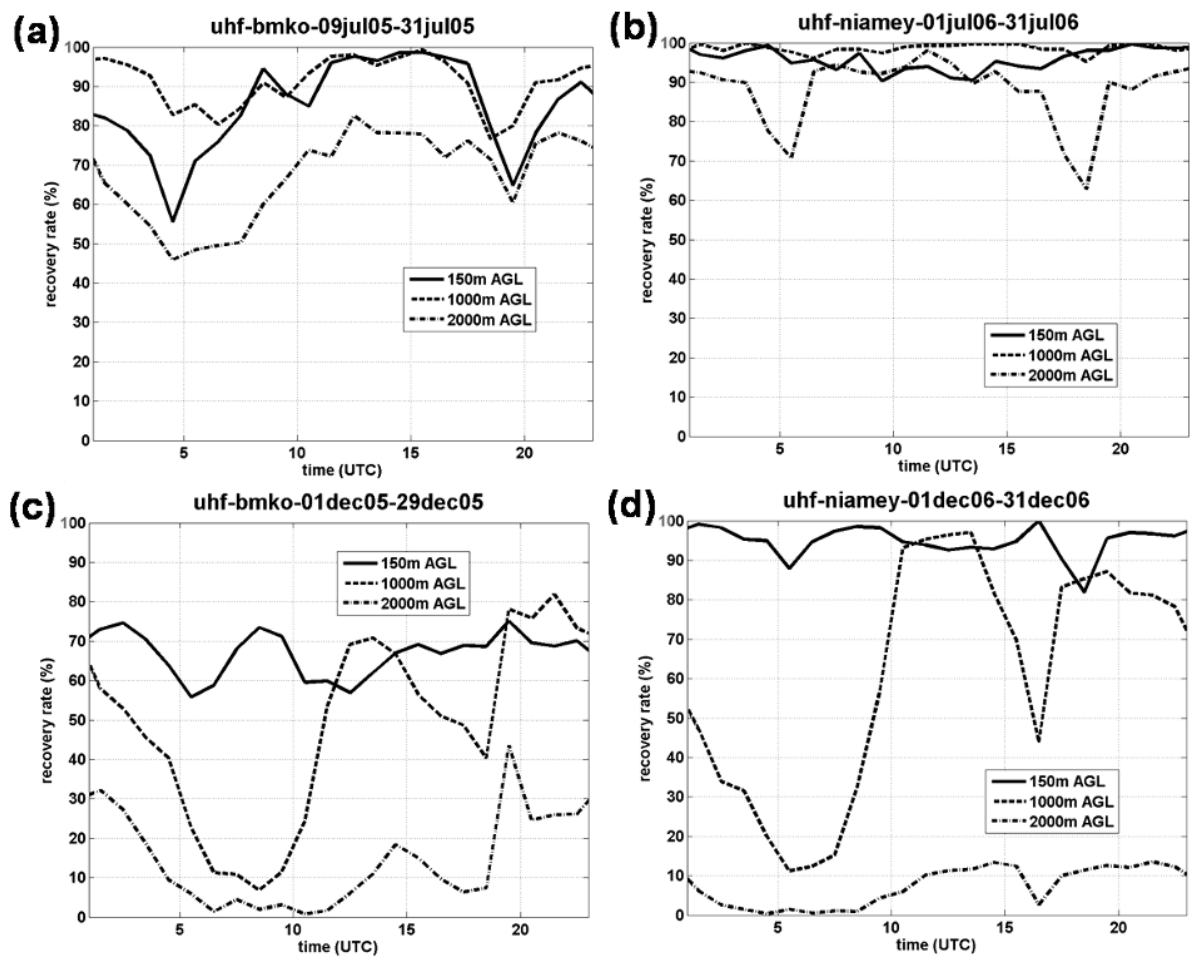

Fig. 2. UHF radar data recovery rate (number of valid data records collected versus the number possible over the month) at 150, 1000, and $2000 \mathrm{~m}$ agl, at Bamako (left panels) and Niamey (right panels), during July (rainy season) and December (dry season).

that a recovery rate of $60 \%$ at one level means at least 345 measurements per day, which is a much better time resolution than that of the radiosoundings.

Other works have reported some problems with the contamination of the first gate range of the profilers, and the difficulty of detecting the LLJ peak in some cases. Zhong et al. (1996) who used the NOAA wind profiler network in the US Great Plains (404 MHz Doppler radars), with a first gate level at $250 \mathrm{~m}$, had to start from the second range gate, at $500 \mathrm{~m}$, to avoid contamination. Whiteman et al. (1997) also observed that they sometimes missed the LLJ peak with $404 \mathrm{MHz}$ radars but that the $915 \mathrm{MHz}$ wind profiler radar could report winds averaged over $102 \mathrm{~m}$ height intervals, beginning at $138 \mathrm{~m}$ agl. Kaplan et al. (2000) also reported successful use of a $915 \mathrm{Mhz}$ wind profiler, with a first gate at $100 \mathrm{~m}$, at Dallas (US) airport, when studying the low-level wind shear associated with the LLJ. The higher the frequency is the thinner the vertical resolution and the lower the first 
gate. Here, we use 1290 and $915 \mathrm{MHz}$ radars that provide satisfactory low level measurements starting at $150 \mathrm{~m}$.

\subsection{Comparison between radar wind profiles and radiosoundings}

The UHF wind profiler radars have been operated during several previous campaigns and comparisons have been made with other instruments such as rawisondes and SODAR (Jacoby-Koaly 2002, Heo et al. 2003). Nevertheless, we found it important to validate measurements in a new environment like the Sahel, where the air is drier than at mid-latitudes.

The comparison with the Niamey radiosoundings (RS) was performed during three characteristic periods (dry, wet, and transition). Results are shown in Fig. 3a, c, and e as the difference in wind velocity between the RS and the radar measurements. Standard deviation of the difference is also shown. Whatever the level, the average absolute value of the differences is lower than $1 \mathrm{~m} / \mathrm{s}$ during May (transition period) and July (wet period), but around $1 \mathrm{~m} / \mathrm{s}$ during December (dry period). This bias is similar to the value reported by May (1995) in Australia $(1 \mathrm{~m} / \mathrm{s})$. Standard deviations of the wind component differences could reach $2 \mathrm{~m} / \mathrm{s}$ during May and July, and $3 \mathrm{~m} / \mathrm{s}$ during December. This comparison shows very good agreement, especially considering that larger differences often occur from a vertical shift between the peaks of the wind profiles. In these cases, the discrepancy would disappear if the UHF profile was shifted $100 \mathrm{~m}$ downwards. The largest variability in December is consistent with the fact that the peak of wind speed (and subsequently the gradient) is larger during the dry season. These discrepancies occur more frequently during the night but are not systematic at all levels. This shift still remains unexplained. May (1995) indicates that, in his comparison (including the seasonal cycle of the Australian monsoon), the amplitude of the jet was possibly underestimated by about $1-2 \mathrm{~m} / \mathrm{s}$ relative to the radiosoundings.

A comparison with another means of measurement of the wind component (MIT C-band Doppler radar) during July showed wind peak levels closer to the UHF radar ones than to the radiosounding ones (not shown here). This was to be expected since rawisonde profiles are nearly instantaneous snapshots of wind structure, while the radar data are averages of winds within fixed atmospheric volumes, and within a 1-hour period. The resolution volume is a $50-\mathrm{m}$-high slice of a cylinder of $15 \mathrm{~km}$ radius in the case of the MIT radar. It is a 60-m-high slice of a cone with a $12^{\circ}$ angle for the UHF.

In order to further investigate the differences, we compared the wind estimations at low level, to check whether the ground clutter echoes might damage the comparison. Results are shown in Fig. 3b, d, and f, as scatterplots 
(a)

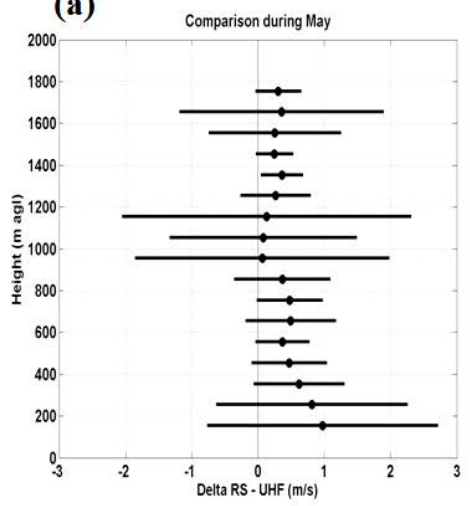

(c)

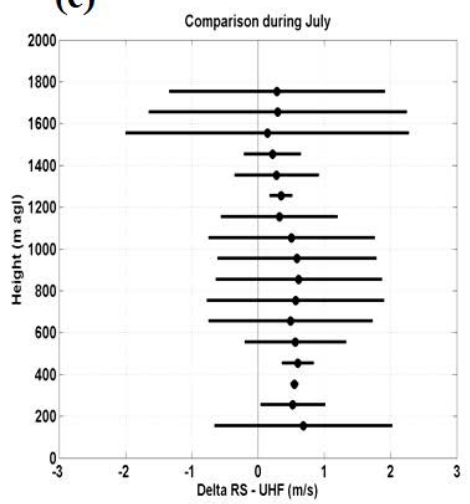

(e)

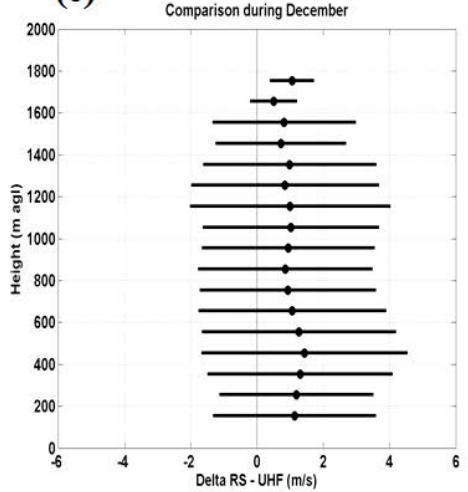

(b)

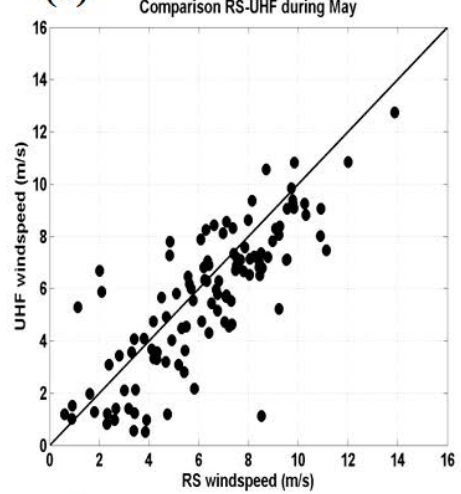

(d)

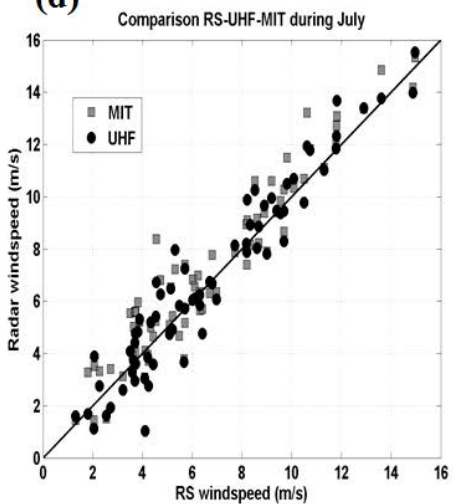

(f)

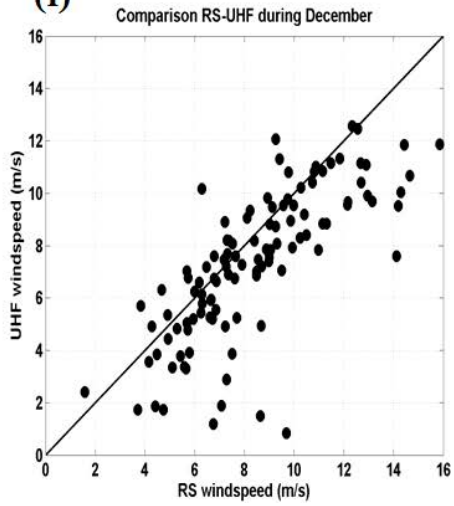

Fig. 3 (left): Difference in the wind velocity estimations between radiosoundings and Niamey UHF radar during the transition (May), wet (July), and dry (December) periods. Note the different scale on the wind axis for December. (right) Scatterplots of the radiosoundings (RS) windspeed against the radars (UHF - black symbols and MIT - gray symbols) windspeed, at $150 \mathrm{~m}$ agl, in Niamey and during the same periods. 
of the radars against RS measurements at $150 \mathrm{~m}$ agl for the 3 periods. During May (Fig. 3b) and as expected, the data are grouped around the 1:1 slope but weak wind values are underestimated by the radar. The comparison is very good in July (Fig. 3d) where the MIT radar winds have also been added. In December (Fig. 3f), stronger winds are not captured by the radar (as discussed before) but weak winds seem still more numerous. This underestimation of the weak wind values by the radars is probably due to the difficulty the computation process has in distinguishing between the ground clutter echo peak in the radial velocity spectrum and the meteorological peak. This is directly linked to the loss of sensitivity that was underlined for the dry season in the previous subsection. It will imply a slight underestimation of the wind potential.

In conclusion, this comparison showed the reliability of the radar measurements, in spite of a slight underestimation of the weak winds during any season and of the strong winds during winter. It was interesting since it concerned three very different measurement techniques, with different targets for the radar electromagnetic echoes.

Unfortunately, radiosoundings could not be used for a similar comparison at Bamako since the vertical resolution of the RS profiles was too poor. This was because high resolution radiosounding data were not available in Bamako in 2005. However, as the reliability of the UHF Degrewind radar at mid-latitudes has already been proved, we consider that the good results obtained at Niamey relative to the UHF detection in a dry atmosphere can be applied to Bamako.

\subsection{Discussion of wind velocity averages}

The standard period for averaging the wind for wind energy potential is ten minutes (AWS Scientific Inc. 1997). Except for wind direction, the average is defined as the mean of all samples. As our reference level $(150 \mathrm{~m})$ was higher than the usual reference level for wind energy (usually lower than $50 \mathrm{~m}$ ), we decided to extend the averaging period to 1-hour (and as mentioned earlier, the data processing had previously filtered out the time-scales shorter than 1 hour in any case). A 1-hour average provides an estimate of winds that covers the whole turbulence range, even for larger time-scales like nighttime ones. Druilhet and Durand (1997) considered that 5 times the height of measurement was a good approximation of the size of the daytime largest eddies in the surface layer, which gives $5 \times 150=750 \mathrm{~m}$. Taking an order of magnitude for statistical representativeness and dividing by a mean wind speed of $2 \mathrm{~m} / \mathrm{s}$ for the worst cases, this leads to $3750 \mathrm{~s}$, which is close to 1 hour. 
When we consider the wind energy potential of a site, the driving parameter is essentially the wind magnitude. Whatever the direction is, it is the wind intensity which will cause the rotation of the rotor blades. That is why, in this case, the average is taken with the wind magnitude and not with the components. However, the direction variability is also an important parameter to be taken into account to obtain an idea of the wind variability and the possible damage to turbines (see Section 5.3 for more discussion).

\section{LARGE SCALE FORCING AND SEASONAL VARIABILITY IN THE ATMOSPHERIC CHARACTERISTICS OF WEST AFRICA}

Our knowledge of the West African monsoon has been recently updated by Lafore et al. (2011) after numerous studies that were carried out during the AMMA experiment. Several works emphasized the role of the pressure minimum, called the heat low (HL), generally confined below $700 \mathrm{hPa}$ and situated over the Sahara, around $22^{\circ} \mathrm{N}, 2^{\circ} \mathrm{W}$ during summer (Lavaysse et al. 2009). On its southern flank, the HL drives the convergence of two opposing low-level flows along the inter-tropical discontinuity (ITD): a warm, dry north-easterly wind called the Harmattan and a cooler, moist south-westerly wind which is the monsoon. According to Lafore et al. (2011), "the resulting strong baroclinicity across this discontinuity, together with associated contrasts in convection, is responsible for the midlevel African easterly jet" (AEJ) whose core is at $4 \mathrm{~km}$ at the latitude of Niamey during this season (Kalapureddy et al. 2010). Rain and extensive cloud cover limit the diurnal temperature variation to about $8^{\circ} \mathrm{C}$ (in the Sahel) as can be seen in the Niamey surface data (Fig. $1 \mathrm{c}$ : from 26 to $34^{\circ} \mathrm{C}$ on average in July).

During winter, due to the course of the Sun, the HL is displaced from $22^{\circ} \mathrm{N}, 2^{\circ} \mathrm{W}$ to $8-9^{\circ} \mathrm{N}, 20^{\circ} \mathrm{E}$ (Lavaysse et al. 2009) and the dry, hot Harmattan blows over most of West Africa. The temperature diurnal variation in the dry season averages $14{ }^{\circ} \mathrm{C}$ (Fig. 1c: from 17 to $31^{\circ} \mathrm{C}$ ). This difference in the temperature range between the two seasons is similar to that reported by May (1995) for the Australian monsoon: $6{ }^{\circ} \mathrm{C}$ in summer (rainy season) and $16^{\circ} \mathrm{C}$ in winter (dry season). The north-eastern Harmattan wind extends over around $2000 \mathrm{~m}$ vertically. At the latitude of Niamey, it is topped by the SubTropical Westerly Jet (STWJ) (Lafore et al. 2011).

April-May and October are transition periods in Bamako and Niamey since the ITD is located at $12-13^{\circ} \mathrm{N}$ during these periods, i.e., close to the latitudes of Bamako and Niamey. Surface humidity measured in May and October in Niamey shows intermediate values between the moist summer conditions (14-16 g/ $/ \mathrm{kg}$ ) and the dry winter ones ( $3 \mathrm{~g} / \mathrm{kg}$ ) (Fig. 1d). However, the situation is more complicated due to the diurnal displacement of the ITD, 
linked to local convection during daytime (Lothon et al. 2008, Flamant et al. 2009, Canut et al. 2010, Pospichal et al. 2010). The ITD oscillates around Niamey or Bamako latitude, during the course of the day, so that the sites are alternatively affected by the monsoon or the Harmattan. This can be seen from the abrupt shift in the wind direction experienced between nights (southwesterly wind) and days (easterly wind) in Niamey during October (Fig. 1b). Bamako (in 2005) experienced the humidity increase 15 days before Niamey in 2006. This shift was associated with a late onset of the rains in Niamey in 2006 (Janicot et al. 2008). Note also that Niamey is located almost one degree of latitude north of Bamako. Niamey received less rain $(650 \mathrm{~mm} / \mathrm{yr})$ in 2006 than Bamako $(1040 \mathrm{~mm} / \mathrm{yr})$ in 2005. As usually in the Sahel, all the precipitation fell in the summer months (April-May to October).

\section{DIURNAL CYCLE OF DYNAMICS AND THERMODYNAMICS}

\subsection{Characteristics of the diurnal cycle}

The good vertical resolution and time resolution of the Niamey radiosoundings in 2006 allowed an analysis to be made of the lower troposphere. The aim was to highlight the variability of thermodynamics during the day, in relation with the dynamics and the period of the year. Figure 4 shows some characteristic examples of the dynamics and thermodynamics time evolution from the surface to $1800 \mathrm{~m}$ agl for two months, characteristic of the dry season (December) and the rainy season (July). Wind, temperature $\theta_{v}$ (virtual potential temperature) and $q$ profiles are represented without any vertical smoothing. We have also represented the 6-hour heat storage $\Delta \theta_{v}$, calculated from two successive soundings. As an index of turbulence, we also computed the gradient Richardson number:

$$
R_{i}=\frac{g \frac{\Delta \theta_{v}}{\Delta z}}{\theta_{v m}\left[\left(\frac{\Delta u}{\Delta z}\right)^{2}+\left(\frac{\Delta v}{\Delta z}\right)^{2}\right]} .
$$

This parameter is frequently used when turbulent data are not directly available. Mahrt et al. (1979) and Banta et al. (2006) reported it to be an appropriate marker of $Z_{x}$, the LLJ peak level. Mahrt et al. (1979) defined the jet height as "the upper bound to the vertical extent of significant turbulent transport of momentum". Banta et al. (2006) further refined the definition of $Z_{x}$ to be "the height of the first wind speed maximum above the surface, 

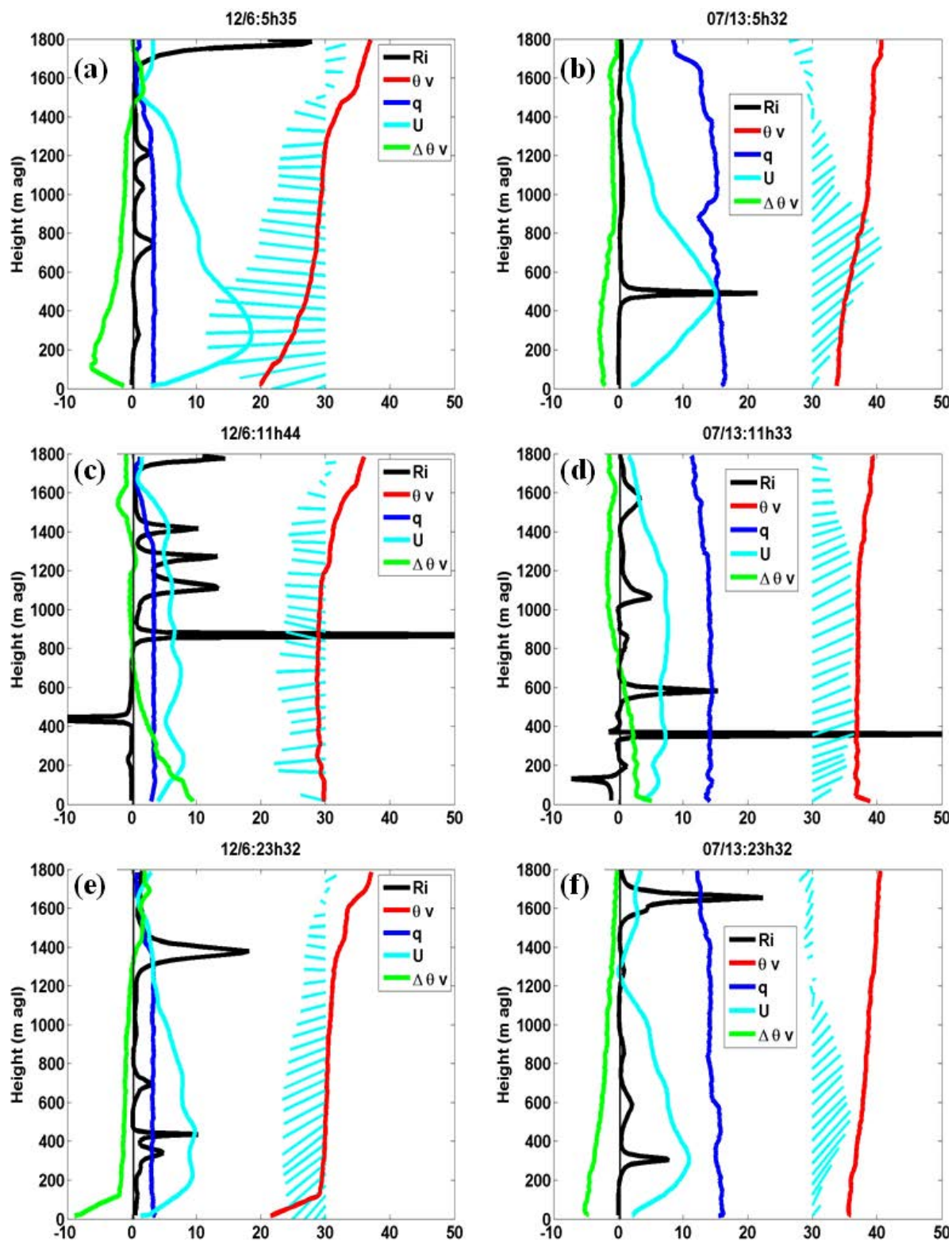

Fig. 4. Radiosounding profiles observed over Niamey in (left) December and (right) July, during a diurnal cycle: $\theta_{v}$ is the virtual potential temperature $\left[{ }^{\circ} \mathrm{C}\right], q$ the water vapour mixing ratio $[\mathrm{g} / \mathrm{kg}], U$ the windspeed $[\mathrm{m} / \mathrm{s}], \Delta \theta_{v}$ the 6 -hour heat storage $\left[{ }^{\circ} \mathrm{C}\right]$, and $R_{i}$ the gradient Richardson number. The critical Richardson number is marked with the thin vertical line. The wind vector is also indicated. 
representing the depth of the surface-base shear layer". At the jet maximum or "nose" (so called by Banta et al. 2006), shear becomes zero, implying suppressed turbulence whereas stratification remains significant. For this reason, $R_{i}$ should achieve a maximum at $Z_{x}$.

Figure 4a-c-e describes a whole diurnal cycle for the dry season conditions. Figure $4 \mathrm{a}$ shows a significant Harmathan LLJ (eastern wind) at 05:35 UTC (the Sun rises at 06:00 UTC), peaking at $Z_{x}=300 \mathrm{~m}$ and reaching $18 \mathrm{~m} / \mathrm{s}$. At the same level, $R_{i}$ reaches 1 , a local maximum. The $\theta_{v}$ profile indicates a stable surface inversion layer extending up to $Z_{\text {inv }} \approx 600 \mathrm{~m}$, which corresponds to the area where the cooling (negative heat storage between 23:32 UTC on previous day and 05:35 UTC on current day) is the strongest. Mahrt et al. (1979), using wind and temperature profiles from the Wangara experiment in a semi-arid area in Australia, previously highlighted the fact that the surface inversion layer may extend above the nose. In fact, the coincidence between the top of the inversion layer and the nose level is usually encountered but not always. Bonner's (1968) climatologic study indicated that only half of his observations showed a coincidence between the two levels. The numerical results from André et al. (1978) attributed the discrepancy between $Z_{\text {inv }}$ and $Z_{x}$ to clear air radiative cooling. At 11:45 UTC, surface heating and turbulence causes the mixed layer to develop to $Z_{i}=1200 \mathrm{~m}$ (Fig. 4b). The LLJ has disappeared and the wind has weakened. $Z_{i}$ still increases until sunset which occurs at 17:25 UTC (not shown). At this time, conditions are almost neutrally stratified due to the pre-existing well mixed conditions. At 23:30 UTC, the cooling has been weak, except within the first $180 \mathrm{~m}$ and the LLJ is diffuse, up to $1650 \mathrm{~m}$, the level where the STWJ starts to blow (Fig. 4c). The cooling will start again afterwards, due to the clear air conditions and the LLJ nose will clearly occur again, at $300 \mathrm{~m}$ on the following day (not shown).

Figure 4b-d-f compares the dry season to the full monsoon conditions. The peak maximum is obvious at 05:32 UTC (sunrise is at 05:36 UTC) (Fig. 4d). It reaches $15 \mathrm{~m} / \mathrm{s}$ and coincides at $Z_{x}=500 \mathrm{~m}$ with a peak in $R_{i}$. The difference with the previous case is that the peak is a monsoon LLJ (south-easterly wind) that brings humidity in the lower layers. The value of $q$ is $15-16 \mathrm{~g} / \mathrm{kg}$ at $05: 32$ UTC below $1400 \mathrm{~m}$, whereas it remains close to 2-3 $\mathrm{g} / \mathrm{kg}$ in the whole low troposphere throughout the day during the dry season. During the rainy season, the cooling rate is almost constant between the surface and $Z_{x}$ and the inversion layer below the nose is almost adiabatic, partly due to the cloud cover that reduces the radiation cooling, partly to the temperature advection that balances the radiative cooling (monsoon air is cool). The monsoon wind is weak at 11:33 UTC (Fig. 4d) and extends above the mixed layer top (which is at $1300 \mathrm{~m}$ ). The value of $q$ reaches its minimum, 
$14 \mathrm{~g} / \mathrm{kg}$, at 18:09 UTC (not shown). Note that, at this time, the $q$ profile and temperature profiles are almost homogeneous, up to $1800 \mathrm{~m}$, on account of the surface heating and entrainment process between the mixed layer and the free troposphere (Canut et al. 2010). The mixed layer top is in this case higher than the shear level between the monsoon and the Harmathan, located at $1300 \mathrm{~m}$. The LLJ is obvious again at 23:32 UTC (Fig. 4f), in a weakly stable layer just over an adiabatic layer of $200 \mathrm{~m}$ (with roughly constant cooling). The LLJ is still diffuse and $R_{i}$ is no longer a good tracer for the nose level.

We can conclude from these examples that the LLJ takes place in the Harmathan or in the monsoon flow according to the season. The associated stability conditions within which it develops also vary: rather strong stable conditions in winter, neutral or weakly stable ones during the rainy or transition seasons. When the LLJ is well marked, $R_{i}$ is a good tracer of $Z_{x}$. We can also note that in these cases, the wind profile is almost linear below $Z_{x}$.

\subsection{Statistics of NLLJ peak}

The monsoon LLJ in West Africa is important because it is a large-scale process which redistributes moisture horizontally in the lower layers during nighttime. The moisture is then transported vertically in the lower troposphere due to turbulence. Recent simulations from French and Parker (2010) emphasize how LLJs can impact the development of nocturnal mesoscale convective systems (MCS) by altering the wind shear in the lower layers. During winter, the LLJ still exists but it does not carry moisture. This section supplements the statistics of LLJ peak observed at Niamey in 2006 and reported by Lothon et al. (2008) with the statistics of Bamako in 2005. The aim is to quantify the inter-seasonal variability at both sites and to show its repetitiveness in the Sahel.

The statistics include the time of the LLJ maximum speed, its intensity, its level and the monthly frequency of occurrence. Three criteria need to be met to define a LLJ peak: (i) maximum wind between 0 and $1000 \mathrm{~m}$, (ii) minimum difference of $2 \mathrm{~m} / \mathrm{s}$ between the intensity of the peak and the maximum wind during the day, and (ii) no convective system. Results are shown in Fig. 5. Due to the level of the first gate of both radars, the statistics cannot include LLJ noses that would be situated below $150 \mathrm{~m}$. Banta et al. (2003) found several cases where the nose of the jet is at such low levels. This limitation of the instrument has to be noted.

At Bamako, the peak intensity of the jet varies between 8 and $22 \mathrm{~m} / \mathrm{s}$ (Fig. 5c). The peak intensity is scattered in this range whatever the season (Fig. 5a). At Niamey, although the maximal intensity of the jet varies in the same range, it decreases from 20 to $8 \mathrm{~m} / \mathrm{s}$ from the beginning of the transi- 
(a) max jet characteristics Bamako in 2005

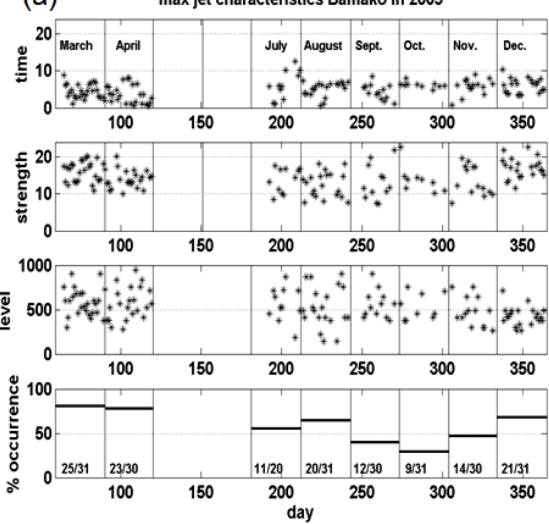

(c)
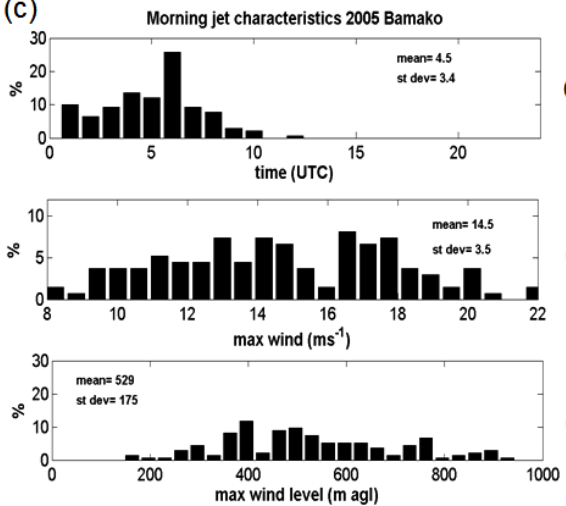

(b)

(i)

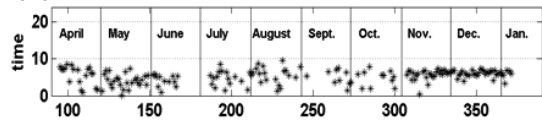

(ii)

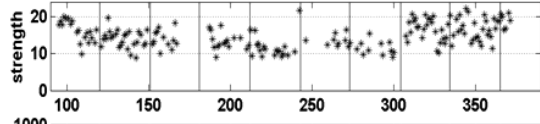

(iii)

(iv)

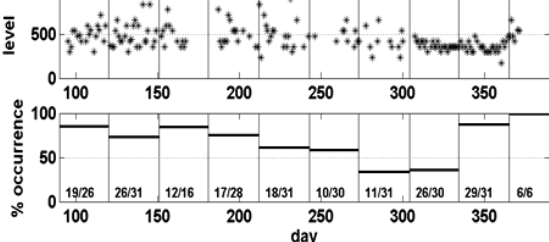

(d)

(i)

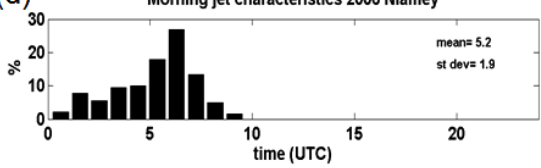

(ii)

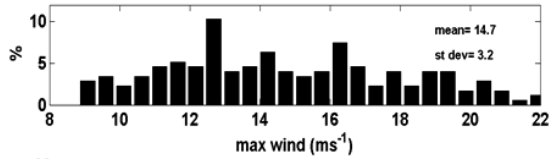

(iii)

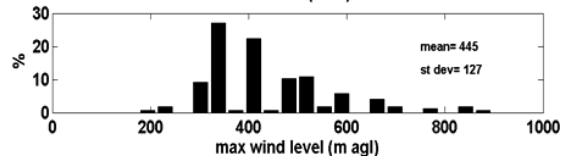

Fig. 5 (top): NLLJ characteristics in (a) Bamako 2005, and (b) Niamey 2006 with (i) the time of occurrence of maximum speed (in UTC), (ii) its intensity (in $\mathrm{m} / \mathrm{s}$ ), (iii) its height (in $\mathrm{m} \mathrm{agl}$ ), and (iv) the monthly frequency of occurrence of the NLLJ, based on UHF wind profiler observations. The ratio in (iv) is the sample size over the number of occurrences of the NLLJ. (bottom): Distribution of the NLLJ peak characteristics at (c) Bamako 2005, and (d) Niamey 2006 with (i) the time of occurrence of maximum jet, (ii) its intensity, (iii) its height, based on the UHF wind profiler observations. "Mean" stands for the average and "st dev" for the standard deviation.

tion period (April-May) to the end of the rainy season (October) (Fig. 5b). It reaches its maximum $(22 \mathrm{~m} / \mathrm{s})$ during the dry season. The peak intensity is much more variable during the dry season.

The statistics of the time and maximum level of the jet are steady in Niamey from November to January: the jet maximum occurs around 05:00 UTC and $450 \mathrm{~m}$ (Fig. 5b). These two parameters are more scattered during the rainy season. The peak levels are then situated between 400 and $800 \mathrm{~m}$ and the strongest peaks occur between 00:00 and 08:00 UTC. This is 
probably due to the disturbances linked to the MCS which bring additional forcing and destroy the LLJ conditions. In Bamako, we do not find the steady conditions mentioned for the dry season in Niamey: the jet maximum is scattered between 150 and $900 \mathrm{~m}$, with a most likely occurrence around 04:30 UTC. The difference in the density of the jet height distributions is linked to the different vertical resolution of both radars.

In Niamey, as in Bamako, the occurrence of the jet decreases from $80 \%$ to $30-40 \%$ from the dry/moist transition to the end of the rainy season including the moist/dry transition period (Fig. 5a and b). It increases again to 90 and $95 \%$ in November and December in Niamey, and to only $70 \%$ in December in Bamako. The fact that the data recovery rate of the radars is not so good during the dry season (Section 2.2) does not interfere with the LLJ frequency of occurrence in Niamey since this frequency is highest in winter. In contrast, the LLJ remains at low levels in December, below the level of loss of sensitivity $(600 \mathrm{~m})$. The LLJ peak percentage of occurrence is generally lower at Bamako than at Niamey. This time, the decrease in data recovery rate at Bamako in winter for gates higher than $430 \mathrm{~m}$ may affect the detection of the jet peak.

The percentage of data showing nocturnal jets in Niamey and Bamako is larger than the percentage reported by May (1995) for the Australian area (during two years), but the seasonal trend is similar: they found $20-25 \%$ during the summer monsoon, $32-54 \%$ during the winter dry season, and $48-78 \%$ during the transition periods.

Average and standard deviation of the distributions of the LLJ peak at Bamako and Niamey are indicated in Fig. $5 \mathrm{c}$ and d. The average time of occurrence of the jet peak is around 05:00 UTC, just before sunrise, but the Bamako LLJ can also be large at any time between midnight and 10:00 UTC, as indicated by the standard deviation. Usually, the maximal velocity for the peak is reached after maximal cooling in the lower layers, which frequently occurs at the end of the night, at least in winter, when the surface cooling is the largest. We have no means of comparing cooling at the two sites because of the poor time and height resolution of the Bamako radiosoundings. Other characteristics (mean level and intensity) are also close: the mean level of the maximum of the jet is $529 \mathrm{~m}$ in Bamako and $445 \mathrm{~m}$ in Niamey, which is in a range of heights that is very frequently found in the literature. The two values are similar, considering the difference in vertical resolution (60 and $150 \mathrm{~m}$, respectively). It is a little more variable at Bamako. The mean annual maximum jet is $14.4 \mathrm{~m} / \mathrm{s}$ in Bamako and $14.7 \mathrm{~m} / \mathrm{s}$ in Niamey, with a slightly higher variability in Bamako. Considering that the larger average in Niamey is linked to the dry season values (Fig. 5b) and considering the loss in data recovery associated with this season in Bamako, we will not comment this difference. 
The summer results are consistent with those from Abdou et al. (2010) who reported the highest value of the peak intensity to be $12.5 \mathrm{~m} / \mathrm{s}$, at $600 \mathrm{~m} \mathrm{agl}$ and 06:00 UTC, during July and August 2006 near Niamey. For the dry season, the results can be favorably compared to those from Washington et al. (2006) who observed LLJ maxima of $18 \mathrm{~m} / \mathrm{s}$ at $700 \mathrm{~m}$ that could occur at any time of night during February and March 2005, over the Bodélé depression in Chad. Note, however, that the Bamako and Niamey LLJ peaks are on average closer to the surface. Mahrt (1981) reported $10 \mathrm{~m} / \mathrm{s}$ maximum wind peaks at $500 \mathrm{~m}$, during seven clear nights, 7 hours before sunrise, at Wangara (in Australia during the dry season).

\subsection{Why is there such a difference between dry and rainy seasons?}

We saw with the previous statistics that dry season LLJs in Niamey are stronger and at lower levels than during the other seasons. Figure 6 shows the scatterplots of the LLJ peaks intensities against their levels, measured with the UHF in Bamako (Fig. 6a) and in Niamey (Fig. 6b), for 3 different periods. In Fig. 6c, we have added an equivalent for the radiosounding measurements in Niamey, with the following slight difference: the peaks observed at fixed times with the RS are peak values for the corresponding profile and not maximum peak values of the night. Note that, among the RS measurements, no maximum has been found below $150 \mathrm{~m}$.

As seen before, there is a positive correlation between the intensity of the LLJ nose and its level as evidenced by the correlation coefficients indicated in the figures and obtained from linear regressions applied to the data. The tendency depends on the month: in Niamey, full monsoon LLJs are on average weaker and higher than winter LLJs. Low-level jets from the transition period are in between. These tendencies are less marked in Bamako. The RS data in Niamey show similar tendencies.

\subsubsection{More stable conditions in winter, due to clearer skies and no cooling due to advection}

This feature can be partly explained by the stability conditions that were encountered below the jet nose. In Fig. 6d, we show a scatterplot of the LLJ height against the virtual potential temperature gradient measured with the RS, in the 50-200 m layer agl. As suggested with Fig. 4, stable conditions are encountered during the dry season (temperature gradients exceeding $1^{\circ} \mathrm{C} / \mathrm{m}$ ). During this period LLJ noses are not higher than $400 \mathrm{~m}$ agl. Note that UHF observations in Niamey show LLJ noses between 300 and $500 \mathrm{~m}$ (Fig. 6b) whereas the radiosounding wind maxima are located between 170 and $400 \mathrm{~m}$ agl (Fig. 6d). This discrepancy comes from the fact that the peak indicated by the RS is probably not the LLJ peak value of the corresponding night. During the rainy or transition periods, the stability conditions close to 

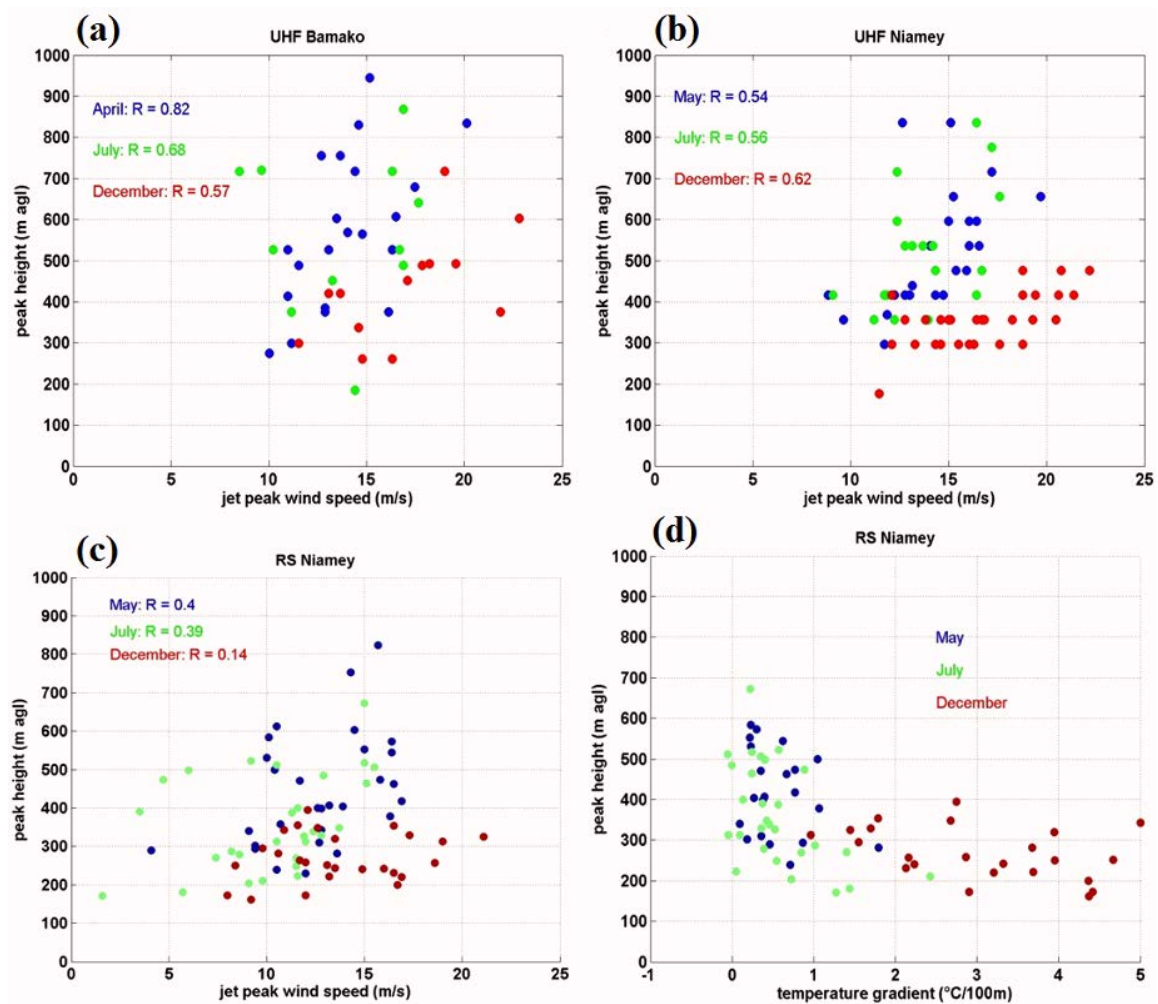

Fig. 6. Scatterplots of the LLJ peak height and velocity at (a) Bamako, and (b) Niamey measured with the UHF; (c) Scatterplot of the maximum wind and its level, measured during the early morning radiosoundings in Niamey, i.e., close to the time of the LLJ maximum; (d) Scatterplot of the maximum wind level and the virtual potential temperature gradient in the [50-200 m] layer, obtained with radiosoundings. $R$ is the correlation coefficient of a linear regression applied to each group of data.

the surface are closer to neutrality and the LLJ develops over an almost neutral layer, probably on account of the different origin of the cooling: radiative cooling in winter that decreases as $Z$ increases, smaller radiative cooling in summer, due to the cloud cover, and vertical divergence balanced with the advection of cooler air in the LLJ. During these periods, LLJ noses lower than $300 \mathrm{~m}$ are also found with the UHF in Bamako.

\subsubsection{Stronger turbulence during daytime in winter}

As reported in the literature and as mentioned above, the LLJ strength depends on the departure from ageostrophic balance: the weaker the wind is during daytime (usually due to strong turbulence), the stronger the inertial acceleration is supposed to be, after turbulence relaxing (Parker et al. 2005). 
The heat surface flux is higher during the dry season than during the wet season (Miller et al. 2009, Ramier et al. 2009). This results in stronger turbulent mixing that decreases the ageostrophic wind component accordingly during the day and intensifies the amplitude of the inertial oscillation when turbulence is relaxed at sunset. This explanation holds to explain the increase in the velocity of the LLJ maximum between July and December. However, the increase in solar flux between winter and summer in Niamey smoothes the difference in available energy at the ground surface somewhat, and the difference in daily heat surface flux is not so large $\left(50 \mathrm{~W} / \mathrm{m}^{2}\right.$ in winter for 40 in summer).

\subsubsection{Periodic increase in the daytime wind intensity around the monsoon onset}

During summer, the strength of the LLJ is also linked to the strength of the daytime monsoon wind. Its variability has previously been raised by several authors. Couvreux et al. (2010), using ECMWF analysis and AMMA observations, highlighted successive northward excursions, called "surges", of the monsoon flux. These surges have a characteristic time-scale of 3-5 days. They are present from April to October but occur very regularly before the monsoon onset with the largest intensification and deepening of the monsoon flow. According to Couvreux et al. (2010), monsoon surges occur following a minimum of pressure level at the Saharan HL, which induces an acceleration of the northward flux at the eastern side of the HL (due to the cyclonic rotation). This is accompanied by a northward displacement of the ITD. The cooling linked to the advection of the monsoon flow in turn destroys the heat low and the monsoon flux decreases. Then the HL is restored in a few days by solar radiation and dry convection.

The intensification of the heat low increases the strength of the ageostrophic wind and therefore the unbalance when turbulence relaxes, producing stronger LLJs, alternating with periods of weaker ones due to the oscillations in the moisture advection. The attraction of the monsoon wind due to the HL in association with still cloud-free days and the strongest turbulence in the year, explains the potentially higher values of the LLJs in May compared to July and August. During the full monsoon period, there are other mechanisms that blur the simplicity of these processes. They are due to the more frequent occurrence of mesoscale systems and to moist convection or to mesoscale circulations due to surface moisture heterogeneities, which add other sources of variability. That is why the LLJ peak frequency of occurrence is smaller during the rainy season.

To the best of our knowledge, heat low conditions relative to the dry season period have been studied far less. The cooling and moistening effect of the monsoon flow, which inhibits the HL deepening over the Sahara in 
summer, is not present in winter since the wind is steady Harmattan (warm and dry) all over the Sahel (remember that the winter HL is situated far to the south-east at $8-9^{\circ} \mathrm{N}$ ). So winter LLJs can develop more freely than summer ones.

\subsubsection{Shear stress with the AEJ during summer but no shear stress with the STWJ during winter}

In spite of the various remarks in this section that lend support to this hypothesis, we conjecture that taking only the turbulence of the preceding day and the strength of the ageostrophic wind into account is not sufficient to explain the mechanism of the LLJs in both seasons. In fact, we tried to find relationships between the LLJ peaks and the turbulence of the preceding convective day, which we quantified by the turbulence kinetic energy dissipation rate, measured with the UHF, and integrated during daytime. We also tried to relate the morning peak intensity to the previous late afternoon boundary layer height. No correlation was found. We think that the situation is greatly complicated by the presence of the opposite winds that blow in the lower and upper layers of the Sahelian low troposphere. As said previously, the AEJ tops the monsoon wind in summer while the STWJ tops the Harmattan wind in winter. Strong shear takes place at the interface and this shear, which is not likely to disappear at night, when turbulence due to convection relaxes, interacts with the wind balance. Kalapureddy et al. (2010) highlighted some contrasted interactions, due to momentum transfer, between the AEJ intensity, the HL intensity and the boundary layer development, during the period from the pre-monsoon to the full monsoon. To look more closely at a potential effect of the free troposphere wind, we tried to find relationships between different characteristic levels in the low troposphere, which were: $Z_{x}$, the height where the LLJ peaks, $Z_{s}$, the level of maximal shear in direction at the interface between the two superposed flows, and $Z_{c}$, the top level of the layer cooled during the previous 6 hours. A clear positive correlation (not shown) was found between $Z_{x}$ and $Z_{s}$, during May and July, with respective correlation coefficients of 0.59 and 0.63 , whereas no correlation was found during December. In December, $Z_{x}$ remained very steady, whatever $Z_{s}$. This result can be partly explained by the divergent anti-cyclonic circulation that takes place in summer in the upper layers, on the northern flank of the intertropical convergence zone (Peyrillé and Lafore 2007), which would tend to confine the low level circulation to the surface, and also to promote momentum exchanges that may interact with the LLJ oscillation. In December, the upper layer circulation is cyclonic in the STWJ and furthermore, there is a deep interface of low wind between the surface Harmattan and the STWJ. 
Nonetheless, we will end by emphasizing the contrasting effect of the cooling already mentioned: $Z_{c}$, normalized by $Z_{s}$, varies as follows according to the season: $1.15 \pm 0.67$ in May, $1.1 \pm 0.71$ in July, and $0.76 \pm 0.32$ in December, which confirms the determining effect of the radiative cooling close to the surface in winter (steady $Z_{c}$ values lower than $Z_{s}$ ), and of the monsoon cool air advection during summer, at a level that is often higher than the monsoon layer $\left(Z_{c}\right.$ values higher than $\left.Z_{s}\right)$.

\section{CHARACTERISTICS OF DYNAMICS AND THERMODYNAMICS IN THE LOWER LEVELS}

In the previous section, we started studying the levels close to the surface to highlight the stability conditions in the lowest layers. In this section, we will pay special attention to the first $200 \mathrm{~m}$ above the surface with the following main objective: to study a way to extrapolate the sub-jet wind from one level to the other and describe the wind characteristics at three different levels. Another issue is to confirm the difference in stability conditions, below the jet level, between the dry period and the rainy period. Niamey radiosounding measurements will be used here so as to look at the lowest levels and to know the thermodynamic conditions.

\subsection{Gradients between 50 and $200 \mathrm{~m}$ agl}

As the first gate level of the radars was $150 \mathrm{~m}$ agl and since one objective of our work was to use the wind energy in the first 100-200 m, we specially studied the wind velocity gradients in the first layers above the ground. This allowed the wind energy to be calculated at different hub heights of the wind turbines.

In the surface layer, i.e., roughly in the first 50-100 m, two methods are commonly used to extrapolate the wind from one level to another: the logarithmic law and the power-law. The first states that the velocity varies logarithmically with height in the surface layer, following:

$$
U(Z)=\frac{u_{*}}{k}\left[\ln \left(\frac{Z}{Z_{o}}\right)+\Psi_{m}\left(\frac{Z}{L}\right)\right]
$$

(Arya 1988), where $Z_{o}$ is the roughness length, $k$ is the Von Karman constant (0.4), and $\Psi_{m}$ is a function that depends on the stability conditions (Paulson 1970). The friction velocity $u *$ is assumed to be constant in the surface layer.

Although the power-law profile does not have a theoretical basis, it usually provides a reasonable fit to the observed velocity profiles (Arya 1988). It allows the wind at level $Z$ to be estimated from the wind measured at 


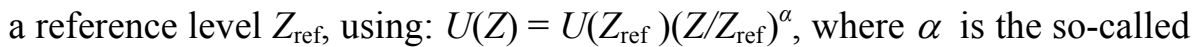
wind-shear or wind power-law coefficient and is typically $1 / 7$ for a smooth surface under neutral conditions. The power-law profile is frequently used in wind potential studies to extrapolate the wind velocity from a low level (the standard reference level is $10 \mathrm{~m}$ ) to a wind-turbine tube height (Archer and Jacobson 2003, Livingston and Anderson 2004, Rehman and Al-Abbadi 2008, Gualtieri and Secci 2011, among others). Although $\alpha=0.2$ is the standard in wind turbine design codes, many authors report larger coefficients which is not surprising since $\alpha$ depends on local roughness, stability condi-

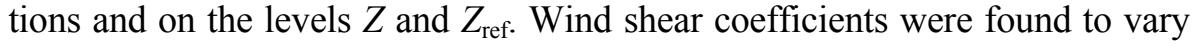
from 0.1 to 0.2 during daytime, and 0.2 to 0.5 during nighttime in the works cited above, according to the roughness of the site and calculation levels.

When profiles have to be extended to higher elevations, the logarithmic law and the power-law no longer apply, although the latter is still commonly used at higher heights. Boundary-layer scales and stability have to be considered. Gryning et al. (2007) calculated appropriate length scales for the different layers, and Kelly and Gryning (2010) used a probabilistic approach to the stability distributions. Anyhow, Drechsel et al. (2012) showed, with a study of wind profiles from meteorological towers and wind turbines at heights between 20 and $250 \mathrm{~m}$ for various European sites, that a linear interpolation between neighbouring levels, especially from the $Z=100 \mathrm{~m}$ level, gives a good approximation of the profile outside the surface layer.

Our data show sub-jet velocity profiles that are close to linear between the ground and $200 \mathrm{~m} \mathrm{agl}$, as can be checked from RS in Fig. 4a and b. We therefore used the radiosounding profiles and re-plotted the wind against height, using a linear regression, between 50 and $200 \mathrm{~m}$ agl. These two levels were chosen to avoid the logarithmic shape of the very first layers while remaining below the jet nose. The correlation coefficients of the regressions for the whole sample of radiosounding profiles were partitioned according to the time of the day and the period of the year. As the shape of the wind profiles is linked to stability conditions, we also calculated the linear regression of the virtual potential temperature profile. The start at $50 \mathrm{~m}$ agl avoided possible super-adiabatic layers, close to the surface. The wind profiles were found linear during nighttime periods whatever the month (regression coefficients between 0.97 and 0.99 ). Linearity in the temperature profiles was systematically found at night during the dry period. During the daytime and sunset periods, linearity in the wind and temperature profiles was encountered in half of the cases.

The wind gradients range between 1 and $5 \mathrm{~m} / \mathrm{s}$ per $100 \mathrm{~m}$ most of the time except during winter when the sub-jet layer experiences gradients from 4 to $7 \mathrm{~m} / \mathrm{s}$ per $100 \mathrm{~m}$ in the early morning. Although the wind gradients are 
the strongest at this time, early morning is not exactly the time when the temperature gradients are the largest: they extend from 2 to $5^{\circ} \mathrm{C} \mathrm{m} / \mathrm{s}$ per $100 \mathrm{~m}$ in the early morning of December but are larger during early night, with most values falling around $3{ }^{\circ} \mathrm{C} \mathrm{m} / \mathrm{s}$ per $100 \mathrm{~m}$ ). They are seldom larger than $1{ }^{\circ} \mathrm{C} \mathrm{m} / \mathrm{s}$ per $100 \mathrm{~m}$ in May and July. Another interesting point is the decrease in the temperature gradient values between late night and early morning for May and July. Sunset causes weakly stable conditions due to the surface cooling. As mentioned before, the nearly adiabatic temperature gradients observed in the early morning result from both the surface radiation cooling (which decreases with height) and cool advection from the monsoon LLJ (which increases from the surface to the LLJ nose and increases with time). Temperature gradients are therefore weaker in the early morning. During daytime, there are neutral conditions or negative gradients of the temperature due to super-adiabatic conditions that extend over $50 \mathrm{~m}$ agl. There are some weakly stable cases in July, probably after the passage of mesoscale systems or squall lines.

In Section 4, we used $R_{i}$ to locate the level of the nose. We are now going to use it at $150 \mathrm{~m} \mathrm{agl}$, as an indicator of the relative contribution of buoyancy against mechanical turbulence. We discard the cases when $150 \mathrm{~m}$ is too close to the jet nose $\left(R_{i}\right.$ larger than 2$)$. The gradient Richardson number $R_{i}$ is represented in Fig. 7a according to the month and the time of day. Its standard deviation during the month is represented with a vertical line and the time standard deviation within each period with a horizontal line. The black horizontal line stands for the 0.25 critical value which marks the transition between a weakly stable regime where some weak continuous turbulence may exist (between 0 and 0.25 ) and a very stable regime, with sporadic turbulence or no turbulence at all, as long as $R_{i}$ increases.

As expected, midday $R_{i}$ values indicate turbulent regimes $\left(R_{i}<0\right)$ with stronger turbulence in May compared to July and December due to the higher surface fluxes.

The value of $R_{i}$ is close to zero at sunset (near 17:30 UTC) during May and July because of the near-adiabatic profiles of temperature. Turbulence starts decreasing during December due to the stronger radiative cooling at the surface. The conditions evolve to marked stable conditions before midnight for every month, with stronger stable conditions during the dry season, in accordance with the larger temperature gradients. Pronounced stable conditions imply a low LLJ nose as observed in December (Fig. 6b and c), which remains the month with the larger temperature gradients (due to radiative cooling in clear air conditions) and the lower LLJ nose, although the latter rises between the late evening and the early morning (not shown).

For most cases, May, July, and December conditions are weakly turbulent in the sub-jet area in the early morning and their variability is very weak, 

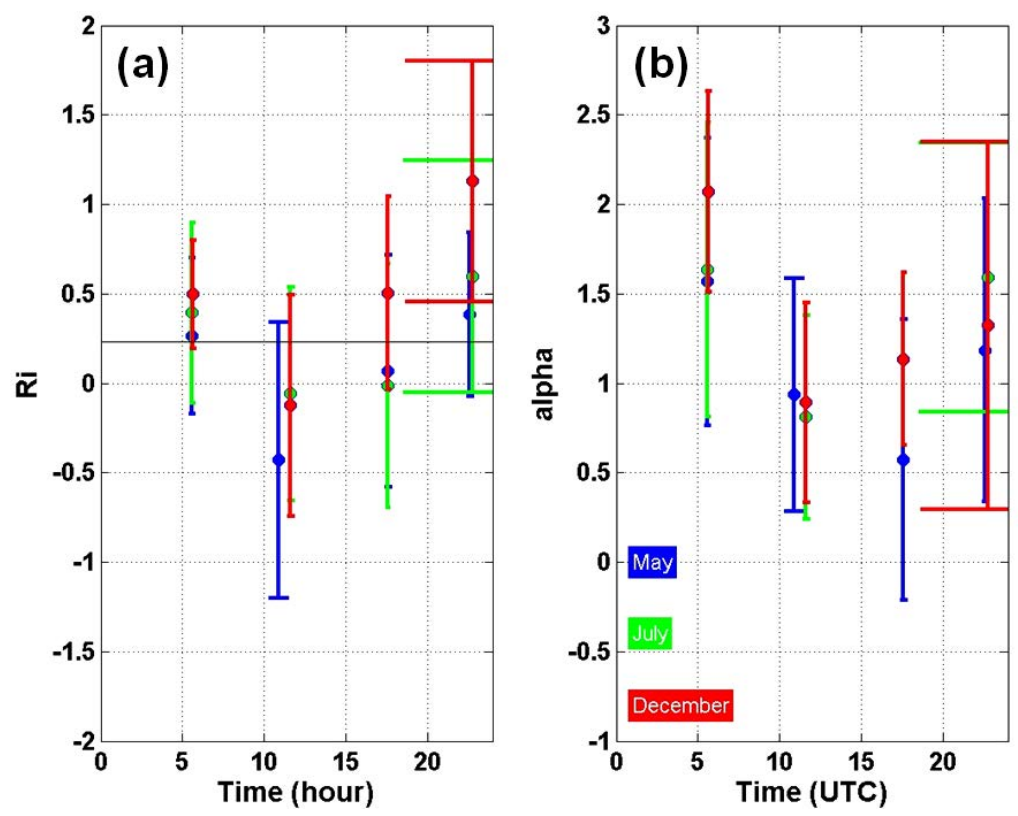

Fig. 7. Diurnal evolution of: (a) the gradient Richardson number, and (b) the powerlaw coefficient, at $150 \mathrm{agl}$ from radiosounding measurements. Vertical bars indicate standard deviations around $R_{i}$ or $\alpha$ averages (dots) while horizontal ones show the time variability of the samples.

compared to the other periods. This could seem to be in disagreement with the larger temperature gradient observed during the night. In fact, it is the increase of mechanical turbulence generated by the LLJ that balances the buoyancy gradient, so that $R_{i}$ values remain weak. The fact that the $R_{i}$ variability is smaller than that of the other periods shows that the effects of the advected cooling and the shear below the LLJ have reached some kind of equilibrium.

Starting from the $R_{i}$ pronounced diurnal cycle and despite the large variability within the stability conditions, we tried to estimate the diurnal cycle of the power-law coefficient retrieved from the RS data. Using the method proposed by Archer and Jacobson (2003), we derived $\alpha$ by fitting a powerlaw profile between 50 and $200 \mathrm{~m}$ agl. The results are shown in Fig. 7b. As expected, very few values are found between 0 and 0.5 , even during daytime conditions. The diurnal cycle is still present, as shown in Arya (1988) and by various other authors, but the $\alpha$ values are far larger than 0.5 and lie between 0.6 and 2.1 on average. Nighttime values are larger than one (one corresponds to a linear profile). This is because the data fit searches for a power-law value in the linear branch of the power function whereas the 
method is not accurate under these conditions. This also explains the variability of $\alpha$. It has proved useless to do the same with the log-profile because of the high variability of the stability conditions (the method proposed by Archer and Jacobson (2003) is based on a log-profile under neutral conditions). This method yielded unrealistic $Z_{o}$ values.

These large and scattered values of the power-law coefficient, together with the large variability in the stability conditions make it impossible to extrapolate the wind from a $10-\mathrm{m}$ reference level, as is frequently done in wind energy studies. We propose here to use the radar data at the first two gates, to estimate the wind gradient and to extrapolate linearly to a lower level. To justify the gradient method, we can argue that we previously found the linear gradient to be relevant for nighttime conditions. For the daytime ones, we keep on applying a linear extrapolation, in accordance with Drechsel et al. (2012) results.

\subsection{Wind characteristics at $150 \pm 60 \mathrm{~m}$}

In the following, we will use UHF observations at 150 and $210 \mathrm{~m}$ agl in Niamey, and 150 and $185 \mathrm{~m}$ in Bamako to retrieve wind at $150 \pm 60 \mathrm{~m}$ by linear extrapolation. $60 \mathrm{~m}$ is roughly the blade length for a turbine rotor height of $150 \mathrm{~m} ; 90 \mathrm{~m}(150 \mathrm{~m}$ minus $60 \mathrm{~m})$ is also the minimum level height where the LLJ is expected according to Abdou et al. (2010). This section presents the $150 \mathrm{~m}$ wind roses in magnitude (average of the wind velocities for 15-deg wind sectors) and frequency (for each 15-deg sector), for summer and winter at Bamako and at Niamey. Wind velocity and direction diurnal cycles at $150 \pm 60 \mathrm{~m}$ agl are also shown.

Figures 8 and 9 show the wind roses of the wet and dry seasons, respectively. July experiences westerlies at both locations with wind velocities in Bamako, not exceeding $5 \mathrm{~m} / \mathrm{s}$ at night and dropping to $3 \mathrm{~m} / \mathrm{s}$ in the evening (Fig. 8a, c). The easterlies that appear in Fig. 8a and b are linked to MCS (Janicot et al. 2008). Their frequency of occurrence is too small to appear in the composite days: for example, the UHF detected 5 MCS moving over Bamako during July, accompanied by easterlies that lasted 2-3 hours after the first rainfall. The vertical variability of the wind is almost constant throughout the day (1-1.5 m s$/ 160 \mathrm{~m}$ at nighttime and 0.5 in daytime). The wind direction does not vary much vertically. The Niamey observations in July are not very different (Fig. 8b, d). Eight MCS were detected by the UHF in Niamey during July, also accompanied by easterlies that could last 8 hours after the first rainfall. On average, the wind is a little higher in Niamey than in Bamako, with more pronounced diurnal amplitude and a similar variability between the 3 levels $\left(1-1.5 \mathrm{~m} \mathrm{~s}^{-1} / 60 \mathrm{~m}\right)$ at nighttime, and smaller in daytime. These wind characteristics are not very favorable for wind farming. 

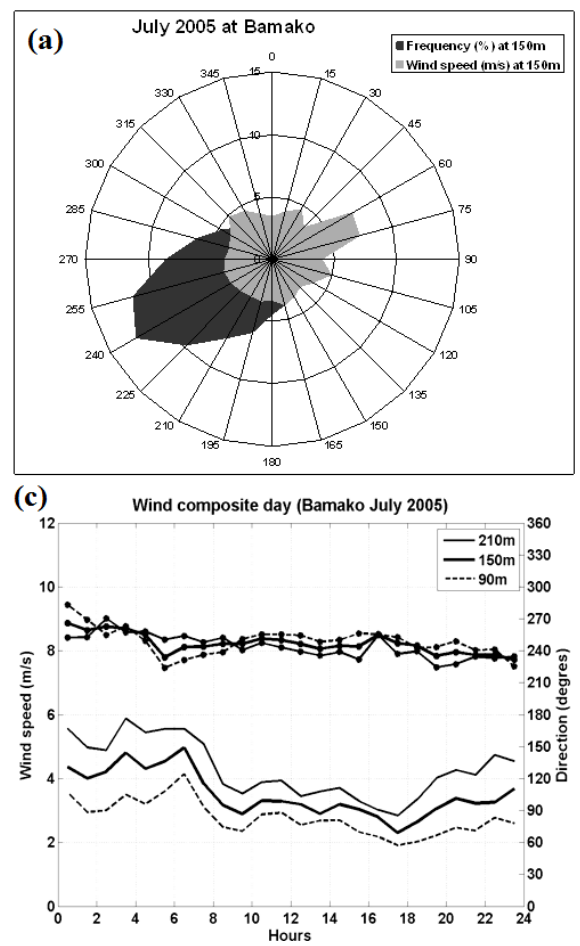
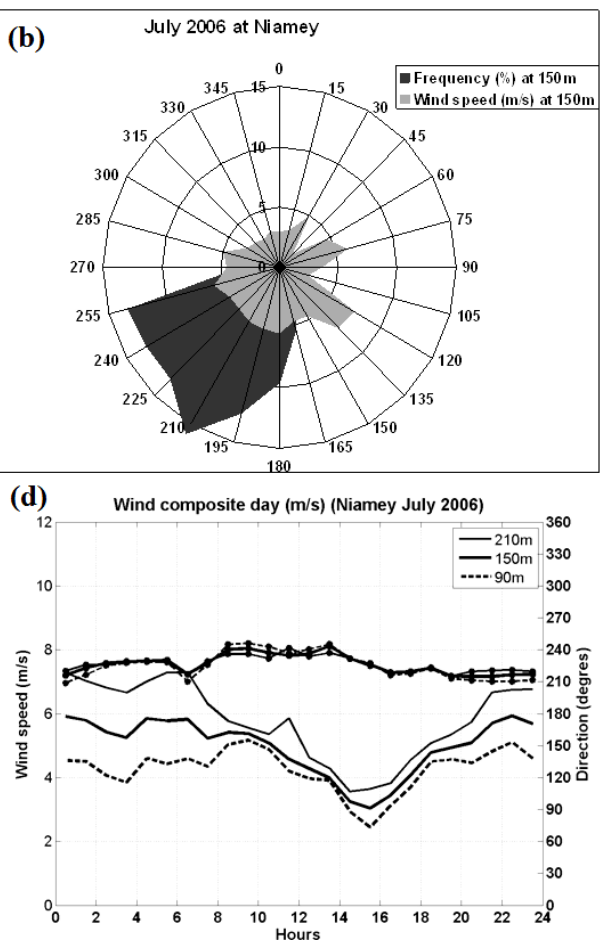

Fig. 8. UHF radar wind roses in magnitude (gray) and frequency (black) at $150 \mathrm{~m}$ agl in July: (a) at Bamako, and (b) at Niamey. Composite day of the wind velocity (solid line) and direction (dotted full line) at $150 \pm 60 \mathrm{~m}$ agl: (c) at Bamako, and (d) at Niamey.

Wind roses indicate that winds have a stronger meridian component in Niamey than in Bamako. This can be explained by the contrast in the locations of the two sites relative to the Saharan HL center, situated at around $2^{\circ} \mathrm{W}$, whereas Bamako is $7^{\circ} \mathrm{W}$ and Niamey $2^{\circ} \mathrm{E}$. These relative positions may also explain the higher nighttime wind values in Niamey compared to those in Bamako.

The wind is steady Harmattan throughout the day during December with, as expected from the previous results on the LLJ peak, a larger diurnal oscillation spanning from 5 to $10 \mathrm{~m} / \mathrm{s}$ (Fig. 9c, d). Those conditions are the most favorable for wind energy exploitation. The vertical gradient is the strongest at nighttime in Niamey and can reach $2 \mathrm{~m} \mathrm{~s}^{-1} / 60 \mathrm{~m}$, whereas the direction veers slightly with height. The maximum velocity at night takes place a few hours after midnight and shifts with time and altitude.

We can conclude from these observations that the windspeed diurnal cycle at $150 \pm 60 \mathrm{~m} \mathrm{agl}$ is drastically different from the surface wind that is 


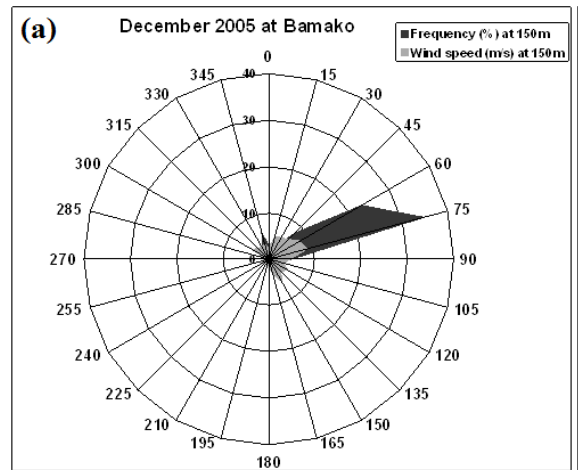

(c)

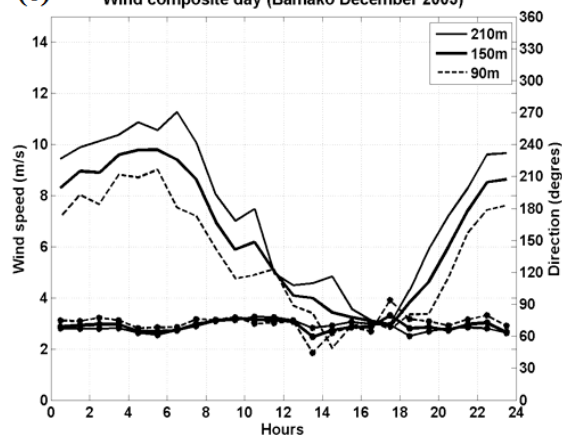

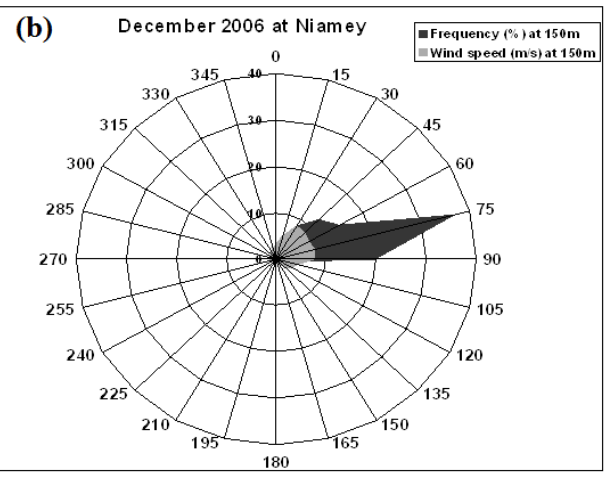

(d) Wind composite day (m/s) (Niamey December 2006)

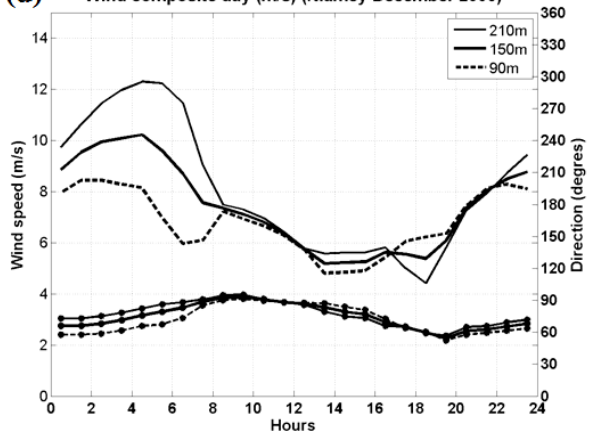

Fig. 9. Same as in Fig. 8 but for December. Note the change in the windspeed and frequency scale in (a) and (b).

shown in Fig. 1a for Niamey, in accordance with previous observations (Parker et al. 2005, Abdou et al. 2010). We can check in Fig. 1a that the peak that appears around 08:00 or 09:00 UTC roughly coincides with the time when convection starts to mix the air below the jet: the 90,150, and $210 \mathrm{~m}$ winds merge in a single curve at this time (Figs. 8 and 9d). However, a daily scatterplot of the peak occurrence time at the surface against the time the mixing starts does not show any clear relationship, except a larger variability in the time occurrence of the mixing (not shown). Surprisingly, the mixing mostly occurs earlier during the dry season, in spite of the more stable conditions below the jet. This is probably due to the higher mechanical turbulence of the dry season jet.

\subsection{Turbulence}

Here we examine the turbulent characteristics of the low level wind to check whether they stay within the nominal range for wind-turbine use. Turbulence is damaging for wind turbines and shortens their life-time. The usual method for assessing turbulence for people dealing with wind potential is to compute 
the standard deviation of wind speed variations, $\sigma_{U}$, over a given period (AWS Scientific Inc. 1997). The turbulence rate, $\tau=\sigma_{U} / U$, characterizes the turbulence intensity during a specified period. $U$ is the wind speed calculated during the same period. Typically, this rate is calculated on averages of 10 min from a 1-min sampling. Note that the "turbulence" described here is not at the same time-scale as the high frequency turbulence commonly used in atmospheric research and reported for instance by Banta et al. (2003).

The sampling period of the UHF radars being at least $5 \mathrm{~min}$, we could not calculate this nominal parameter. So we propose a different estimation of the turbulence rate. We use the same wind samples here as previously, i.e., 1-hour samples which corresponds to 10 profiles in Niamey and 22 profiles in Bamako. Thus our results will be systematically underestimated relative to the standard.

The ranges of 1-hour standard deviations of the wind and corresponding turbulence rates and wind intensity ranges are shown in Table 1 for four months and both locations. As expected, the highest standard deviations were obtained when winds were weak, which subsequently increased the turbulence rate. This rate was between 0.1 and 0.4 in Niamey, with the largest values obtained during the transition periods. The upper limits of the standard deviation and of the turbulence rate in Niamey are the lower ones at Bamako. This is primarily due to the lower wind velocities at Bamako and also to the larger number of samples involved in the average. However, if the same number of profiles is used to process the data as for Niamey, Bamako turbulence rates remain 20 to $30 \%$ higher than Niamey ones. This is likely due to the poorer recovery rate of the data at low level in Bamako.

The International Electro-technical Commission (IEC 2005-2008) 61400-1 wind turbine design standards specify that a turbine must be designed for $\tau$ levels in the range 0.3-0.5, 0.2-0.3, and 0.16-0.24 for wind velocities of $2.5,5$, and $7.5 \mathrm{~m} / \mathrm{s}$, respectively, at the hub height. Note that these normal turbulence conditions are defined by assuming a power-law exponent of 0.2. Niamey turbulence indexes lie in this range. Those from Bamako are larger, but in a range of wind velocity where $\tau$ increases as the infinite branch of a hyperbola. Rehman and Al-Abbadi (2008), who used half hourly monthly average turbulence rates, calculated from 10 min average wind speeds and standard deviations at 20,30 , and $40 \mathrm{~m}$, indicate $\tau$ levels varying between 0.10 and 0.27 according to the month of the year and the time of day, with windspeed centered at 5-6 m/s.

We also used the definition proposed by Yamartino (1984) to compute the wind direction standard deviations. The wind direction variability is listed in Table 1. It can reach, on average, rather large values during 1 hour, such as $73^{\circ}$, in Niamey during May, which nevertheless remains in 
Table 1

Monthly windspeed range, 1-hour wind standard deviation range, turbulence rate $\left(\sigma_{U} / U\right)$ range and wind direction standard deviation range, at both sites at $150 \mathrm{~m}$ agl

\begin{tabular}{|l|l|c|c|c|c|}
\hline Location & Months & $\begin{array}{c}\text { Windspeed } \\
\text { range } \\
{[\mathrm{m} / \mathrm{s}]}\end{array}$ & $\begin{array}{c}\text { Windspeed } \\
\text { standard deviation } \\
\text { range }[\mathrm{m} / \mathrm{s}]\end{array}$ & $\begin{array}{c}\text { Turbulence } \\
\text { rate range }\end{array}$ & $\begin{array}{c}\text { Wind direction } \\
\text { standard deviation } \\
\text { range [deg] }\end{array}$ \\
\hline \multirow{3}{*}{ Niamey } & May & $2.7-7.3$ & $0.6-1.1$ & $0.1-0.4$ & $30-73$ \\
& July & $3.0-5.9$ & $0.3-1.2$ & $0.1-0.3$ & $30-53$ \\
& October & $2.5-5.4$ & $0.4-1.1$ & $0.1-0.4$ & $32-60$ \\
& December & $5.2-10.2$ & $0.3-1.1$ & $0.0-0.2$ & $8-41$ \\
\hline \multirow{5}{*}{ Bamako } & April & $0.7-5.2$ & $1.1-1.9$ & $0.3-1.6$ & $31-54$ \\
& July & $2.3-5.0$ & $1.1-2.5$ & $0.4-0.8$ & $32-59$ \\
& October & $2.7-5.1$ & $1.1-2.2$ & $0.3-0.7$ & $42-57$ \\
& December & $2.9-9.8$ & $1.4-2.6$ & $0.2-0.7$ & $24-45$ \\
\hline
\end{tabular}

the range recommended by the IEC $61400-1$ standard $\left(78^{\circ}\right.$ for a $2.7 \mathrm{~m} / \mathrm{s}$ windspeed). Again, the variability is highest in Niamey (but not in Bamako) during both transition periods. The lowest variability is around $30^{\circ}$, in Niamey or Bamako. It is smaller in winter since the wind is steadier during this season (Fig. 9a and b). The diurnal cycle of the direction variability (not shown) is not strictly linked to the wind intensity. It is not clearly marked in Bamako. The minimum occurs around the time of the LLJ maximum in Niamey, but the maximum is shifted relative to the wind velocity minimum (sometimes a few hours after sunset, before the LLJ is completely established).

In addition, we should take the wind turbine wear and tear by boundary layer aerosols into consideration. Several atmospheric processes favor dust emission and transport in Sahel (Engelstaedter and Washington 2007, Formenti et al. 2008, Rajot et al. 2008, Marticorena et al. 2010). To the best of our knowledge, no information is available yet about the damage this dust could cause on the wind turbines.

\section{CONCLUSIONS}

A statistical analysis of the vertical profile of the wind was performed in two different locations in the Sahel, during 8 months of continuous acquisition, to assess whether the wind conditions are propitious for converting wind energy in these areas or not. These tropical areas are known to experience weak winds at the surface. Nevertheless, the nocturnal jet occurring overnight produces an intensification of the wind speed which has been highlighted by previous works. Among them, Parker et al.'s (2005) study relies on re- 
analyses and a limited number of observations. The authors underline the necessity of obtaining good time-resolution of the observational means, so as to be able to capture the diurnal cycle of the wind. UHF wind profilers, which can provide data every $5 \mathrm{~min}$ (after a 1-hour smoothing), are advantageous to produce these data whereas routine radiosoundings, usually performed at 00:00 and 12:00 UTC as in Bamako, partly miss the nocturnal LLJ. The wind speed intensification arises in the low levels but is not visible at ground level (Washington et al. 2006, Lothon et al. 2008, Abdou et al. 2010, Lohou et al. 2010), which discourages the use of synoptic weather stations and promotes the use of remote-sensing instruments that can provide the vertical profile of the wind.

The analysis performed here confirms and extends the results previously shown in the literature with the significant asset of being the largest database of observed wind profiles in the Sahel area. We confirm that the LLJs previously described for the environs of Niamey by Parker et al. (2005) or Lothon et al. (2008) can also be observed in Bamako, $100 \mathrm{~km}$ away in latitude, in spite of differences relative to the time and height variability that may be due to the different position of the sites relative to the Saharan HL. Many authors have already stressed the crucial role of the HL to explain the high variability in the LLJ intensity during summer (rainy season), especially in the period preceding the full monsoon. We have compared the summer to the winter characteristics (dry season) here. The intensity of the LLJ peaks was found to be larger in winter than in summer, and located at lower level, for various reasons:

a The available energy at the surface is the highest in winter since the net radiative flux is mostly used for convection due to the dry conditions. Turbulence being higher, its suppression after sunset provokes a greater unbalance of the wind components and enhances the LLJ.

- LLJs occur in stable conditions. During winter, the stability is essentially linked to the surface radiative cooling and is greatest near the surface. During summer, the radiative cooling is smaller because of the cloud cover and monsoon cooling occuring at the level of the LLJ. The vertical divergence of the cooling is then smaller and the stability conditions are close to neutrality. LLJs are less marked and develop at higher levels.

a During summer, the depth of the monsoon layer and the intensity of the monsoon are modulated by the oscillations resulting from the interaction between the Saharan heat low and the monsoon cooling effect.

- The depth of the monsoon layer is also probably dependent on the synoptic subsident conditions at its top. As the summer nocturnal cooling is distributed over the whole depth of the monsoon layer, the LLJ is not confined near the surface and not as strong as in winter. In addition, momentum transfer due to the shear stress at the top of the monsoon layer may reduce 
the inertial acceleration that causes the jet at sunset. In contrast, during winter, the LLJ level is not linked to the height of the shear layer between the Harmathan and the STWJ that blows at around $2 \mathrm{~km}$.

The study of the wind profiles below the LLJ level, obtained with rawisondes at $11 \mathrm{~m}$ vertical resolution, confirms the results from previous studies, showing a linear dependence of the wind with the height. This result, however, is not familiar for people conducting wind energy studies. The latter most of the time use the log-profile or the power law profile that clearly cannot be applied in the LLJ conditions.

We used linear profiles for extrapolating the UHF measurements from the first and second gates of the profilers to other levels, 90 and $210 \mathrm{~m}$, taken to be the level of the blade extremities (for a turbine hub situated at $150 \mathrm{~m}$ ). The linear approximation of the wind profile remains valid during the daytime, due to the weak values of the wind during daytime. Wind intensity and direction presented at $150 \pm 60 \mathrm{~m}$ show that the diurnal cycle and the seasonal evolution are still obvious at these levels. The nighttime wind magnitude is large enough to be used by wind turbines but the daytime winds are at the lower limit of the favorable range, most of the time, except in winter. As the wind intensity is easily $2 \mathrm{~m} / \mathrm{s}$ lower at $90 \mathrm{~m}$ than it is at $150 \mathrm{~m}$, the latter level should be preferred. However it is a little too high for the present time turbine technology. The specific configuration of the Niamey surroundings could be used to avoid this problem. To the north-west of the Niger River (and also north-west of the Niamey city), at a height of about $60 \mathrm{~m}$ above the river, laterite plateaux dominate. So $90 \mathrm{~m}$ wind turbines installed on the plateaux would be at $150 \mathrm{~m}$, relative to the Niger River valley. This would allow some increase in the monsoon LLJ that blows from south-west. During winter, the dry season LLJ is strong enough at $90 \mathrm{~m}$ to provide wind energy. In Bamako, there are hills close to the town that could also play the same role.

Wind patterns are highly anisotropic in winter because the Harmattan wind blows steadily. Associated with the largest wind speeds, winter is the season when the turbulence rate is the smallest, which preserves the wind turbines. On the other hand, this is the season when the low level shear is the strongest and we do not know the consequence of this large shear on the rotor blades. In any case, turbulence rates remain reasonable throughout the year for both sites. Even if the turbulence rate associated with the wind velocity variability is moderate and rather constant whatever the month (except winter), the wind direction variability can reach rather large values, especially during the dry/moist transition period. In addition, winter and spring are the seasons when dust transport at the surface is the most frequent, which is an even more damaging factor than turbulence. The present study 
therefore suggests that additional measurements should be made to estimate fatigue loads, perhaps with a wind-turbine used for test purposes (Hayman et al. 2008 discuss the challenges that materials have to face for instance). Under the conditions of our study, there are 5 factors that are critical for wind turbines: large wind shears due to the LLJ, especially for the tall wind turbines required; large turbulent rates and time variability of the wind direction due to the weak winds during daytime; large directional shear and, finally, wear and tear due to aerosols.

This study showed that the minimum level for a turbine hub should be $90 \mathrm{~m}$ in the Sahel area, in association with solar energy during the day and provided the turbines are installed on elevated points. Further studies on a longer period, possibly using other means such as a met tower, a sodar or a Doppler lidar, should be conducted to estimate the cost of such investments and the possibility to associate the energy provided by the wind at nighttime to the solar energy available during daytime.

Acknowledgments. The authors of this work received funds from INSU-CNRS and the University Abdou Moumouni (Niamey, Niger). Based on a French initiative, AMMA was built by an international scientific group and is currently funded by a large number of agencies, especially from France, UK, USA, and Africa. It has been the beneficiary of a major financial contribution from the European Community's Sixth Framework Research Programme. Detailed information on scientific coordination and funding is available on the AMMA International web site http:/www.ammainternational.org. We would like to give special thanks to ASECNA for carrying out the radiosounding operation and providing the UHF profiler data in Bamako. We also thank the USA Department of Energy for operating the radiosounding and the UHF wind profiler in Niamey and providing the data as well as the ground station data, as part of the Atmospheric Radiation Measurement program. We are also grateful to Habib Leseney for providing the IEC international standard. Finally we thank Earl Williams and his team who enabled the comparison with the MIT radar data.

References

Abdou, K., D.J. Parker, B. Brooks, N. Kalthoff, and T. Lebel (2010), The diurnal cycle of lower boundary-layer wind in the West African monsoon, Quart. J. Roy. Met. Soc. 136, S1, 66-76, DOI: 10.1002/qj.536.

Adekoya, L.O., and A.A. Adewale (1992), Wind energy potential of Nigeria, Renew. Energ. 2, 1, 35-39, DOI: 10.1016/0960-1481(92)90057-A. 
Ajayi, O.O. (2009), Assessment of utilization of wind energy resources in Nigeria, Energ. Policy 37, 2, 750-753, DOI: 10.1016/j.enpol.2008.10.020.

André, J.C., G. de Moor, P. Lacarrère, and R. Du Vachat (1978), Modeling the 24hour evolution of the mean and turbulent structures of the planetary boundary layer, J. Atmos. Sci. 35, 10, 1861-1883, DOI: 10.1175/1520-0469(1978) 035<1861:MTHEOT $>2.0$. CO;2.

Archer, C.L., and M.Z. Jacobson (2003), Spatial and temporal distributions of U.S. winds and wind power at $80 \mathrm{~m}$ derived from measurements, J. Geophys. Res. 108, 4289, DOI: 10.1029/2002JD002076.

Arya, S.P. (1988), Introduction to Micrometeorology, International Geophysics Series, Vol. 42, Academic Press, San Diego.

AWS Scientific Inc. (1997), Wind Resource Assessment Handbook, Albany, USA, www.awsscientific.com.

Banta, R.M., Y.L. Pichugina, and R.K. Newsom (2003), Relationship between lowlevel jet properties and turbulence kinetic energy in the nocturnal stable boundary layer, J. Atmos. Sci. 60, 20, 2549-2555, DOI: 10.1175/15200469(2003)060<2549:RBLJPA >2.0.CO;2.

Banta, R.M., Y.L. Pichugina, and W.A. Brewer (2006), Turbulent velocity-variance profiles in the stable boundary layer generated by a nocturnal low-level jet, J. Atmos. Sci. 63, 11, 2700-2719, DOI: 10.1175/JAS3776.1.

Blackadar, A.K. (1957), Boundary layer wind maxima and their significance for the growth of nocturnal inversions, Bull. Am. Meteorol. Soc. 38, 283-290.

Bonner, W.D. (1968), Climatology of the low level jet, Monthly Weath. Rev. 96, 12, 8330850, DOI: 10.1175/1520-0493(1968)096<0833:COTLLJ>2.0.CO;2.

Bousquet, O., and M. Chong (1998), A multiple-Doppler synthesis and continuity adjustment technique (MUSCAT) to recover wind components from Doppler radar measurements, J. Atmos. Oceanic Technol. 15, 2, 343-359, DOI: 10.1175/1520-0426(1998)015<0343:AMDSAC $>2.0 . C O ; 2$.

Canut, G., M. Lothon, F. Saïd, and F. Lohou (2010), Observation of entrainment at the interface between monsoon flow and the Saharan Air Layer, Quart. J. Roy. Met. Soc. 136, S1, 34-46, DOI: 10.1002/qj.471.

Chong, M., and O. Bousquet (2001), On the application of MUSCAT to a groundbased dual-Doppler radar system, Meteorol. Atmos. Phys. 78, 1-2, 133-139, DOI: $10.1007 / \mathrm{s} 007030170011$.

Coulter, R.L., G. Klazura, B.M. Lesht, T.J. Martin, J.D. Shannon, D.L. Sisterson, and M.L. Wesely (1999), The Argonne Boundary Layer Experiments facility: Using minisodars to complement a wind profiler network, Meteorol. Atmos. Phys. 71, 1-2, 53-59, DOI: 10.1007/s007030050043.

Couvreux, F., F. Guichard, O. Bock, B. Campistron, J.-P. Lafore, and J.-L. Redelsperger (2010), Synoptic variability of the monsoon flux over West Africa prior to the onset, Quart. J. Roy. Met. Soc. 136, S1, 159-173, DOI: 10.1002/ qj. 473 . 
Drechsel, S., G.J. Mayr, J.W. Messner, and R. Stauffer (2012), Wind speeds at heights crucial for wind energy: Measurements and verification of forecasts, J. Appl. Meteorol. Clim., DOI: 10.1175/JAMC-D-11-0247.1.

Druilhet, A., and P. Durand (1997), Experimental investigation of atmospheric boundary layer turbulence, Atmos. Res. 43, 4, 345-388, DOI: 10.1016/ S0169-8095(96)00041-5.

Engelstaedter, S., and R. Washington (2007), Atmospheric controls on the annual cycle of North African dust, J. Geophys. Res. 112, D03103, DOI: 10.1029/ 2006JD007195.

Flamant, C., P. Knippertz, D.J. Parker, J.-P. Chaboureau, C. Lavaysse, A. AgustiPanareda, and L. Kergoat (2009), The impact of a mesoscale convective system cold pool on the northward propagation of the intertropical discontinuity over West Africa, Quart. J. Roy. Met. Soc. 135, 638, 139-159, DOI: 10.1002/qj.357.

Formenti, P., J.L. Rajot, K. Desboeufs, S. Caquineau, S. Chevaillier, S. Nava, A. Gaudichet, E. Journet, S. Triquet, S. Alfaro, M. Chiari, J. Haywood, H. Coe, and E. Highwood (2008), Regional variability of the composition of mineral dust from western Africa: Results from the AMMA SOP0/ DABEX and DODO field campaigns, J. Geophys. Res. 113, D00C13, DOI: 10.1029/2008JD009903.

French, A.J., and M.D. Parker (2010), The response of simulated nocturnal convective systems to a developing low-level jet, J. Atmos. Sci. 67, 10, 3384-3408, DOI: $10.1175 / 2010 J A S 3329.1$.

Gifford, F.A. (1952), The breakdown of a low-level inversion studied by means of detailed soundings with a modified radiosonde, Bull. Am. Meteor. Soc. 33, 373-379.

Gryning, S.-E., E. Batchvarova, B. Brümmer, H. Jørgensen, and S. Larsen (2007), On the extension of the wind profile over homogeneous terrain beyond the surface boundary layer, Bound.-Layer Meteorol. 124, 2, 251-268, DOI: 10.1007/s10546-007-9166-9.

Gualtieri, G., and S. Secci (2011), Wind shear coefficients, roughness length and energy yield over coastal locations in Southern Italy, Renew. Energ. 36, 3, 1081-1094, DOI: 10.1016/j.renene.2010.09.001.

Heo, B.-H., S. Jacoby-Koaly, K.-E. Kim, B. Campistron, B. Benech, and E.-S. Jung (2003), Use of the Doppler spectral width to improve the estimation of the convective boundary layer height from UHF wind profiler observations, J. Atmos. Ocean. Technol. 20, 3, 408-424, DOI: 10.1175/1520-0426(2003) $020<0408$ :UOTDSW>2.0.CO;2.

International Electro-technical Commission IEC 61400-1 (2005-2008), Wind turbines, Part 1. Design requirements, IEC, Geneva, Switzerland.

Jacoby-Koaly, S., B. Campistron, S. Bernard, B. Bénech, F. Ardhuin-Girard, J. Dessens, E. Dupont, and B. Carissimo (2002), Turbulent dissipation rate in the boundary layer via UHF wind profiler Doppler spectral width meas- 
urements, Bound.-Layer Meteorol. 103, 3, 361-389, DOI: 10.1023/A: 1014985111855.

Janicot, S., and B. Sultan (2007), The large-scale context of the West African monsoon in 2006. In: 12th CLIVAR Exchanges, International CLIVAR Project Office, April 2007, Southampton, United Kingdom, 11-17.

Janicot, S., C.D. Thorncroft, A. Ali, N. Asencio, G. Berry, O. Bock, B. Bourles, G. Caniaux, F. Chauvin, A. Deme, L. Kergoat, J.-P. Lafore, C. Lavaysse, T. Lebel, B. Marticorena, F. Mounier, P. Nedelec, J.-L. Redelsperger, F. Ravegnani, C.E. Reeves, R. Roca, P. De Rosnay, H. Schlager, B. Sultan, M. Tomasini, A. Ulanovsky, and ACMAD Forecasters Team (2008), Large-scale overview of the summer monsoon over West Africa during the AMMA field experiment in 2006, Ann. Geophys. 26, 9, 2569-2595, DOI: 10.5194/angeo-26-2569-2008.

Kalapureddy, M.C.R., M. Lothon, B. Campistron, F. Lohou, and F. Saïd (2010), Wind profiler analysis of the African Easterly Jet in relation with the boundary-layer and the Saharan heat low, Quart. J. Roy. Met. Soc. 136, S1, 77-91, DOI: 10.1002/qj.494.

Kaplan, M.L., Y.L. Lin., J.J. Charney, K.D. Pfeiffer, D.B. Ensley, D.S. DeCroix, and R.P. Weglarz (2000), A terminal area PBL prediction system at DallasFort Worth and its application in simulating diurnal PBL jets, Bull. Am. Meteor. Soc. 81, 2179-2204, DOI: 10.1175/1520-0477(2000)081<2179: ATAPPS $>2.3 . \mathrm{CO} ; 2$.

Kasbadji-Merzouk, N., and M. Merzouk (2006), Estimation du potentiel énergétique éolien utilisable. Application au pompage dans les Hauts Plateaux, Rev. Energ. Renev. 9, 3, 155-163 (in French).

Kébé, C.M.F., V. Sambou, B. Ould Bilal, P.A. Ndiaye, and M. Los (2008), Evaluation du potentiel éolien du site de Gandon dans la région nord du Sénégal. In: International Meteorology Conference CAFMET 2008, Tunis, Tunisia, 22-24 (in French).

Kelly, M., and S.-E. Gryning (2010), Long-term mean wind profiles based on similarity theory, Bound.-Layer Meteorol. 136, 3, 377-390, DOI: 10.1007/ s10546-010-9509-9.

Lafore, J.-P., C. Flamant, F. Guichard, D.J. Parker, D. Bouniol, A.H. Fink, V. Giraud, M. Gosset, N. Hall, H. Höller, S.C. Jones, A. Protat, R. Roca, F. Roux, F. Saïd, and C. Thorncroft (2011), Progress in understanding of weather systems in West Africa, Atmos. Sci. Lett. 12, 1, 7-12, DOI: 10.1002/asl.335.

Lavaysse, C., C. Flamant, S. Janicot, D.J. Parker, J.-P. Lafore, B. Sultan, and J. Pelon (2009), Seasonal evolution of the West African heat low: a climatological perspective, Clim. Dyn. 33, 2-3, 313-330, DOI: 10.1007/s00382009-0553-4.

Lebel, T., D.J. Parker, C. Flamant, B. Bourlès, B. Marticorena, E. Mougin, C. Peugeot, A. Diedhiou, J.M. Haywood, J.B. Ngamini, J. Polcher, J.-L. Redelsperger, and C.D. Thorncroft (2010), The AMMA field campaigns: 
multiscale and multidisciplinary observations in the West African region, Quart. J. Roy. Met. Soc. 136, S1, 8-33, DOI: 10.1002/qj.486.

Livingston, J.T., and T. Anderson (2004), Wind shear, taller turbines, and the effects on wind farm development create a need for taller MET towers, Windtower Composites Report, LLC, Herber City, USA.

Lohou, F., F. Saïd, M. Lothon, P. Durand, and D. Serça (2010), Impact of boundarylayer processes on near-surface turbulence within the West African monsoon, Bound.-Layer Meteorol. 136, 1, 1-23, DOI: 10.1007/s10546-0109493-0.

Lothon, M., F. Saïd, F. Lohou, and B. Campistron (2008), Observation of the diurnal cycle in the low troposphere of West Africa, Monthly Weath. Rev. 136, 9, 3477-3500, DOI: 10.1175/2008MWR2427.1.

Lothon, M., B. Campistron, M. Chong, F. Couvreux, F. Guichard, C. Rio, and E. Williams (2011), Life cycle of a mesoscale circular gust front observed by a C-band Doppler radar in West Africa, Monthly Weath. Rev.139, 5, 1370-1388, DOI: 10.1175/2010MWR3480.1.

Lundquist, J.K. (2003), Intermittent and elliptical inertial oscillations in the atmospheric boundary layer, J. Atmos. Sci. 60, 21, 2661-2673, DOI: 10.1175/ 1520-0469(2003)060<2661:IAEIOI >2.0.CO;2.

Mahrt, L. (1981), The early evening boundary layer transition, Quart. J. Roy. Met. Soc. 107, 452, 329-343, DOI: 10.1002/qj.49710745205.

Mahrt, L., R.C. Heald, D.H. Lenschow, B. Stankov, and I.B. Troen (1979), An observational study of the structure of the nocturnal boundary layer, Bound.Layer. Meteorol. 17, 2, 247-264, DOI: 10.1007/BF00117983.

Marticorena, B., B. Chatenet, J.L. Rajot, S. Traoré, M. Coulibaly, A. Diallo, I. Koné, A. Maman, T. Ndiaye, and A. Zakou (2010), Temporal variability of mineral dust concentrations over West Africa: analyses of a pluriannual monitoring from the AMMA Sahelian Dust Transect, Atmos. Chem. Phys. 10, 8899-8915, DOI: 10.5194/acp-10-8899-2010.

May, P.T. (1995), The Australian nocturnal jet and diurnal variations of boundarylayer winds over Mt. Isa in North-eastern Australia, Quart. J. Roy. Met. Soc. 121, 525, 987-1003, DOI: 10.1002/qj.49712152503.

Miller, M.A., and A. Slingo (2007), The ARM Mobile Facility and its first international deployment: Measuring radiative flux divergence in West Africa, Bull. Am. Meteor. Soc. 88, 8, 1229-1244, DOI: 10.1175/BAMS-88-8-1229.

Miller, M.A., A. Slingo, J.C. Barnard, and E. Kassianov (2009), Seasonal contrast in the surface energy balance of the Sahel, J. Geophys. Res. 114, D00E05, DOI: 10.1029/2008JD010521.

Ngala, G.M., B. Alkali, and M.A. Aji (2007), Viability of wind energy as a power generation source in Maiduguri, Borno state, Nigeria, Renew. Energ. 32, 13, 2242-2246, DOI: 10.1016/j.renene.2006.12.016. 
Parker, D.J., R.R. Burton, A. Diongue-Niang, R.J. Ellis, M.A. Felton, C.M. Taylor, C.D. Thorncroft, P. Bessemoulin, and A.M. Tompkins (2005), The diurnal cycle of the West African monsoon circulation, Quart. J. Roy. Met. Soc. 131, 611, 2839-2860, DOI: 10.1256/qj.04.52.

Parker, D.J., A. Fink, S. Janicot, J.-B. Ngamini, M. Douglas, E. Afiesimama, A. Agusti-Panareda, A. Beljaars, F. Dide, A. Diedhiou, T. Lebel, J. Polcher, J.-L. Redelsperger, C. Thorncroft, and G.A. Wilson (2008), The AMMA radiosonde program and its implications for the future of atmospheric monitoring over Africa, Bull. Am. Meteor. Soc. 89, 7, 1015-1027, DOI: 10.1175/2008BAMS2436.1.

Paulson, C.A. (1970), The mathematical representation of wind speed and temperature in the unstable atmospheric surface layer, J. Appl. Meteor. 9, 6, 857861, DOI: 10.1175/1520-0450(1970)009<0857:TMROWS >2.0.CO;2.

Peyrillé, P., and J.-P. Lafore (2007), An idealized two-dimensional framework to study the West African monsoon. Part II: Large-scale advection and the diurnal cycle, J. Atmos. Sci. 64, 2783-2803, DOI: 10.1175/JAS4052.1.

Pospichal, B., D. Bou Karam, S. Crewell, C. Flamant, A. Hünerbein, O. Bock, and F. Saïd (2010), Diurnal cycle of the intertropical discontinuity over West Africa analysed by remote sensing and mesoscale modelling, Quart. J. Roy. Met. Soc. 136, S1, 92-106, DOI: 10.1002/qj.435.

Rácz, Z., and R.K. Smith (1999), The dynamics of heat lows, Quart. J. Roy. Met. Soc. 125, 553, 225-252, DOI: 10.1002/qj.49712555313.

Rajot, J.-L., P. Formenti, S. Alfaro, K. Desboeufs, S. Chevaillier, B. Chatenet, A. Gaudichet, E. Journet, B. Marticorena, S. Triquet, A. Maman, N. Mouget, and A. Zakou (2008), AMMA dust experiment: An overview of measurements performed during the dry season special observation period (SOP0) at the Banizoumbou (Niger) supersite, J. Geophys. Res. 113, D00C14, DOI: 10.1029/2008JD009906.

Ramier, D., N. Boulain, B. Cappelaere, F. Timouk, M. Rabanit, C.R. Lloyd, S. Boubkraoui, F. Métayer, L. Descroix, and V. Wawrzyniak (2009), Towards an understanding of coupled physical and biological processes in the cultivated Sahel - 1. Energy and water, J. Hydrol. 375, 1-2, 204-216, DOI: 10.1016/j.jhydrol.2008.12.002.

Redelsperger, J.-L., C.D. Thorncroft, A. Diedhiou, T. Lebel, D.J. Parker, and J. Polcher (2006), African Monsoon Multidisciplinary Analysis: An international research project and field campaign, Bull. Am. Meteor. Soc. 87, 12, 1739-1746, DOI: 10.1175/BAMS-87-12-1739.

Rehman, S., and N.M. Al-Abbadi (2008), Wind shear coefficient, turbulence intensity and wind power potential assessment for Dhulom, Saudi Arabia, Renew. Energ. 33, 12, 2653-2660, DOI: 10.1016/j.renene.2008.02.012.

Shapiro, A., and E. Fedorovich (2010), Analytical description of a nocturnal lowlevel jet, Quart. J. Roy. Met. Soc. 136, 650, 1255-1262, DOI: 10.1002/ qj.628. 
Song, J., K. Liao, R.L. Coulter, and B.M. Lesht (2005), Climatology of the low-level jet at the Southern Great Plains Atmospheric Boundary Layer Experiments site, J. Appl. Meteor. 44, 10, 1593-1606, DOI: 10.1175/JAM2294.1.

Stensrud, D.J. (1996), Importance of low-level jets to climate: A review, J. Climate 9, 8, 1698-1711, DOI: 10.1175/1520-0442(1996)009<1698:IOLLJT> 2.0.CO;2.

Storm, B., and S. Basu (2010), The WRF model forecast-derived low-level wind shear climatology over the United States Great Plains, Energies 3, 2, 258276, DOI: 10.3390/en3020258.

Washington, R., and M.C. Todd (2005), Atmospheric controls on mineral dust emission from the Bodélé Depression, Chad: The role of the low level jet, Geophys. Res. Lett. 32, 17, L17701, DOI: 10.1029/2005GL023597.

Washington, R., M.C. Todd, S. Engelstaedter, S. M'Bainayel, and F. Mitchell (2006), Dust and the low level circulation over the Bodele Depression, Northern Chad, J. Geophys. Res. 111, D03201, DOI: 10.1029/2005JD 006502.

Whiteman, C.D., X. Bian, and S. Zhong (1997), Low-level jet climatology from enhanced rawinsonde observations at a site in the Southern Great Plains, J. Appl. Meteor. 36, 10, 1363-1376, DOI: 10.1175/1520-0450(1997)036 $<1363$ :LLJCFE $>2.0$. CO;2.

World Wind Energy Association (2010), World Wind Energy Report 2010, www.wwindea.org/home/images/stories/pdfs/worldwindenergyreport2010_ s.pdf.

Yamartino, R.J. (1984), A comparison of several "single-pass" estimators of the standard deviation of wind direction, J. Appl. Meteorol. 23, 9, 1362-1366, DOI: 10.1175/1520-0450(1984)023<1362:ACOSPE $>2.0 . C O ; 2$.

Youm, I., J. Sarr, M. Sall, A. Ndiaye, and M.M. Kane (2005), Analysis of wind data and wind energy potential along the northern coast of Senegal, Rev. Energ. Ren. 8, 95-108.

Zhong, S., J.D. Fast, and X. Bian (1996), A case study of the Great Plains low-level jet using wind profiler network data and a high resolution mesoscale model, Montly Weath. Rev. 124, 5, 785-806, DOI: 10.1175/1520-0493(1996)124 $<0785$ :ACSOTG $>2.0$. CO;2. 